\title{
Estrutura de informação como suporte em múltiplas vistas do produto num projeto orientado para a manufatura
}

\author{
Osiris Canciglieri Junior \\ PUC - PR \\ Robert I. M. Young \\ Loughborough University
}

\begin{abstract}
Resumo
Atualmente, as atividades de projeto devem ser muito bem orquestradas e integradas, proporcionando a evolução da filosofia da Engenharia Concorrente, onde decisões sobre diferentes aspectos relacionados ao ciclo de vida do produto devem ser consideradas simultaneamente. Porém, quando todo o projeto orientado para a manufatura é considerado, existem muitos aspectos que devem ser endereçados. Isso conduz à necessidade de sistemas de informações que sejam capazes de auxiliar múltiplas vistas do produto, onde cada vista provê a representação apropriada para auxiliar pelo menos uma perspectiva da manufatura. Essa pesquisa investigou o potencial do sistema baseado no Modelo do Produto para representar múltiplas vistas no Projeto orientado para a manufatura de produtos plásticos injetáveis e explorou em particular a vista da moldabilidade, do projeto do molde (cavidade) e da manufatura do molde [cavidade). A abordagem explorou estruturas de informações particulares para auxiliar cada aplicativo do Projeto Orientado para a Manufatura e um Modelo de Produto experimental foi implementado, utilizando um banco de dados orientado ao objeto.
\end{abstract}

\section{Palavras-chave}

Engenharia simultânea, tecnologia de features, usinagem, modelagem do produto, projeto orientado para a manufatura.

\section{Information structure as support in multiviewpoint of product in the design for manufacture}

\begin{abstract}
Actually the activities of overall design must be well orchestrated and integrated which has led to the evolution of the philosophy of Concurrent Engineering where the decisions about different aspects related to the product's life cycle, must be considered simultaneously. However, when the full breadth of design for manufacture is considered there are many aspects that must be addressed. This leads to the need for information systems to be able to support multiple views of a product, where each view provides the appropriate representation to support at least one manufacturing perspective. This research has investigated the potential of product model based systems to support multiple viewpoints in Design for Manufacture. The research has focused on the design for manufacture of plastic injection moulded products and has explored the particular viewpoints of mouldability, mould design and mould manufacturing. The approach taken has been to explore particular information structures to support each Design for Manufacture application. An experimental Product Model has been implemented using an object-oriented database.
\end{abstract}

Key words

Simultaneous engineering, features technology, machining, product modelling, design for manufacture. 


\section{INTRODUĈ̣̃O}

Atualmente, um problema crucial no desenvolvimento de novos produtos é a necessidade de redução do tempo consumido durante as fases de projeto e manufatura, tentando manter a qualidade requerida a um custo acessível aos consumidores. Para conseguir isso são necessários conhecimentos e experiência em diversas áreas e conhecimento envolvendo consumidores e fornecedores. $\mathrm{O}$ processo de projeto precisa ser muito bem orquestrado e integrado e com isso vem crescendo, nas duas últimas décadas, o interesse pela engenharia simultânea.

A engenharia simultânea é uma importante filosofia para o desenvolvimento de novos produtos e para que consigam chegar ao mercado no tempo adequado. Todavia, enquanto as equipes de projeto apresentam algum sucesso em suas atividades, existe a necessidade de uma evolução radical de softwares ferramenta que ofereçam suporte ao processo de projeto. Um aspecto importante da engenharia simultânea é o Projeto Orientado para a Manufatura (DFM), assim, podese afirmar que é impossível atingir os objetivos de qualidade e custo de fabricação isolando as operações de engenharia de projeto e de manufatura.

O projeto orientado para a manufatura incorpora no processo de projeto, informações referentes a manufatura e isso auxilia a manter a comunicação entre todos os elementos de um sistema de manufatura, permitindo, ainda, que o projeto possa ser adaptado durante cada estágio da realização do produto (BOOTHROYD et al., 1993). Um outro aspecto importante é a resistência da irreversibilidade das decisões para a otimização dos produtos e seus respectivos processos de manufatura. Todavia, os objetivos da abordagem do DFM são identificar os conceitos dos produtos que deverão ser fabricados e montados mais facilmente, garantindo os requisitos definidos pelo projeto.

Sistemas de projeto devem integrar as atividades de projeto, de manufatura, banco de dados e sistemas computacionais especialistas (WILLEMS et al., 1995). Estes sistemas devem oferecer suporte aos times de engenharia, promovendo acessos consistentes às informações fontes do produto e da manufatura, e ainda promover suporte a decisões que deverão ser tomadas.

A tecnologia de features deveria prover uma melhor integração entre o projeto e as atividades de manufatura através da análise de elementos finitos, do planejamento do processo, da usinagem, da fixação de produtos e dispositivos, entre outros (SALOMONS et al., 1993). Entretanto, pesquisadores têm explorado de maneira limitada a tecnologia de features, já que as features têm sido utilizadas, tipicamente, somente para representar um ponto de vista do produto, como por exemplo a modelagem geométrica, a usinagem, a montagem, etc. Dessa maneira, para se obter maior potencialidade, os sistemas integrados de projetos devem unir um elenco de diferentes vistas do produto plástico injetável, como, por exemplo, vista geométrica, vista funcional, vista de moldabilidade, vista de manufatura, entre outras. Abordagens atuais são incapazes de atingir essas necessidades (ALLADA; ANAND, 1995; CANCIGLIERI, 1999; YOUNG et al., 2000; CANCIGLIERI; YOUNG, 2003; CANCIGLIERI et al., 2001).

Este artigo explora o potencial da utilização da abordagem das features em combinação com técnicas de modelagem de informação promovendo um conjunto (set) compreensivo de informação que possa oferecer suporte ao projeto de vários pontos de vistas da manufatura. Cada conjunto de informação (set) pode ser visto como uma forma de suporte à tomadas de decisão, referenciado para aspectos da forma ou de outros atributos do produto, podendo ser utilizado como uma forma de raciocínio do projeto ou na manufatura do produto. Este artigo apresenta também contribuição na área de sistemas de suporte ao projeto orientado para a manufatura, utilizando os bancos de dados de produto e de manufatura, que fornecem informação apropriada para cada ponto de vista do produto. Esta pesquisa foi aplicada na área de produtos plásticos injetáveis para provar as idéias propostas pelos autores.

\section{SISTEMAS DE INFORMAC̄̃̃O PARA O SUPORTE A EQUIPES DE PROJETO}

\section{Sistema do Modelo de Dados}

Atualmente, a maioria das pesquisas sobre metodologias de "Projeto Orientado para a Manufatura - DFM" enfatiza simplesmente um processo de fabricação, como por exemplo, projeto orientado para a montagem, projeto orientado para a usinagem, projeto orientado para a fixação, entre outros. Entretanto, se forem considerados os problemas reais de projeto com certeza existirão muitos processos de fabricação envolvidos e, para cada um deles, o sistema deverá oferecer a oportunidade de inserção de conhecimento/experiência nas tomadas de decisões durante as fases de execução do projeto.

Canciglieri e Young (1997) apresentaram os requerimentos de um sistema de raciocínio que é capaz de converter informação, entre duas vistas distintas do produto, dentro de um ambiente de engenharia concorrente. Na pesquisa eles apresentaram um exemplo de features de mouldabilidadede um produto plástico injetado que continha informações referentes à geometria do produto, a localização da linha de partição, as tolerâncias dimensionais e de forma, entre outros, que foram convertidas em termos de features de projeto da cavidade do molde e estas, convertidas em termos de features de manufatura da cavidade do molde. Neste caso, vários elementos, como a influência do plástico no projeto 
do molde e qual processo de manufatura deve ser usado para fabricar o molde (cavidade). As características de cada processo de manufatura podem ser capturadas no banco de dados Modelo de Manufatura (Manufacturing Model). Isso permite que a função estrategista acesse as informações no modelo de manufatura e identifique quais são significantes e envie uma resposta (feedback) para as equipes de projeto, quando necessário. computacionais estão sendo desenvolvidas com o intuito de auxiliar os projetistas a analisar as limitações da manufatura nos estágios iniciais do projeto.

Tipicamente, o sistema de projeto orientado para a manufatura provê apoio somente para um processo, por exemplo, projeto orientado para a montagem (BOOTHROYD; DEWHURST, 1990), projeto orientado para a usinagem (LU; MOLDI, 1997; DONG; VIJAYAN, 1997), projeto orientado para a moldabilidade do plástico (CUTKOSKY et al., 1989), e assim por diante. Gupta et al. (1997) apresentaram um estudo sobre análise sobre a habilidade da manufatura automatizada. A pesquisa desenvolvida por Boothroyd e Dewhurst (1990) foi considerada pioneira para o desenvolvimento das diretrizes do projeto orientado para a montagem. Depois deles, vários trabalhos de pesquisa

Enquanto que as características de cada processo podem ser capturadas no banco de dados modelo de manufatura, um problema mais crítico seria o de como prover a inserção de dados, de maneira apropriada, no modelo de manufatura para cada processo. Existe também a necessidade de prover uma vista dos dados referente, ao produto numa forma adequada para cada processo de manufatura. Por esta razão, Young (1996) propôs que isso pode ser provido através do Modelo de Produto (Product Model), onde seria possível capturar as diferentes perspectivas do produto necessárias para cada ponto de vista de manufatura. Em adicional, existe ainda a necessidade de um processo de conversão que possa manter as diferentes perspectivas do produto, facilitando a manipulação das informações por vários aplicativos de projeto orientado para a manufatura.

\section{Projeto Orientado para a Manufatura}

Estudos mostraram que a maior parte do custo total do produto é determinada nas fases de projeto (COBERTT, 1986; WHITNEY, 1990; ULLMAN, 1992; SUH, 1992; DOWLATSHAHI, 1994). Estes resultados têm guiado pesquisadores a identificar e criar metodologias orientadas para o projeto visando a manufatura dos produtos. O Projeto Orientado para a Manufatura (DFM) tenta conciliar simultaneamente as metas de projeto com as limitações da manufatura, evitando problemas de fabricação em estágios posteriores do ciclo de vida de produto. Isto também promove a redução do tempo de desenvolvimento do produto e melhora sua qualidade. Tradicionalmente, engenheiros e projetistas continuam desenvolvendo projetos com poucas considerações de manufatura. No caso da manufatura, subseqüentemente à identificação de problemas no projeto, será necessário pedir às equipes de projetistas as devidas soluções. Para reduzir o risco do reprojeto, ferramentas foram desenvolvidos baseados nesta metodologia. Hsu et al. (1993) desenvolveram um sistema de suporte resultando em avaliação da montagem automatizada. Li e Hwang (1992) desenvolveram um sistema semi-automatizado. Sturges e Kilani (1992) sugeriram uma modificação nesta metodologia. Boothroyd (1994) apresentou uma metodologia de projeto orientado para a manufatura e montagem aplicadas em diferentes companhias.

Subramanyan e Lu (1991) voltaram sua pesquisa para vários aspectos dos problemas de manufaturabilidade, incluindo problemas de fixação, ferramental, aferição e manipulação de material. A pesquisa desenvolveu um sistema de avaliação da manufatura para peças rotacionais. Priest e Sanchez (1991) e Sanchez et al. (1992) desenvolveram um método empírico de projeto baseado na classificação dos fatores da capacidade de produção para medir a manufaturabilidade das peças usinadas. Miyakawa (1991) desenvolveu um sistema de avaliação para analisar a capacidade de produção através do melhoramento da metodologia do projeto orientado para a montagem e também apoiando o processo de usinagem. Esta análise dá feedback aos custos da manufatura. Huh e Kim (1991) descreveram um sistema especialista para apoiar o projeto simultâneo de produtos de plásticos injetáveis. $\mathrm{O}$ sistema está baseado em regras para diferentes materiais plásticos e apóia a síntese das características suplementares que serão colocadas no projeto inicial. O sistema auxilia o engenheiro projetista a executar tarefas como, por exemplo, a determinação de exigências das nervuras, secções cruzadas de nervuras, quantidade de nervuras e projeto de ressaltos circulares.

Wozny et al. (1993) desenvolveram uma representação unificada para apoiar o projeto orientado para a manufaturabilidade, que integra muitas fases do projeto e manufatura. A abordagem considera os múltiplos processos de manufatura 
quando avalia as peças. O sistema pode, também, oferecer sugestões para o reprojeto e considerar a montagem das peças. Ishii et al. (1993) desenvolveram uma ferramenta computacional de projeto compatível para análise para auxiliar o projeto de produto baseado em várias considerações de seu ciclo de vida. O sistema usa uma base de conhecimento compatível para avaliar falhas entre vários elementos de projeto e requisitos funcionais. Yannoulakis et al. (1994) desenvolveram um sistema para avaliação da manufaturabilidade de peças rotacionais usinadas em centros de torneamento. Eles usam a abordagem de tecnologia de features em que a manufaturabilidade é calculada baseada em estimativa do tempo de usinagem com técnicas empíricas para estimar parâmetros de corte e tempo de usinagem. Todavia, o método não considera tolerâncias geométricas ou alternativas de features.

Chen e LeClair (1994) desenvolveram um sistema baseado em funções de objetivos múltiplos para geração do set-up (dados de preparação de máquinas) e o sequenciamento de features que usam funções com objetivos múltiplos para o set-up propriamente dito e a geração de seqüenciamento das ferramentas. Gupta e Nau (1995) descreveram uma metodologia para avaliar a capacidade de manufatura, na fase inicial de projeto, orientada para usinagem de componentes prismáticos. A metodologia está baseada na forma geométrica e na tolerância de cada operação para gerar o plano de operação. Fauvel (1994) baseou-se na hipótese de que o conceito de manufaturabilidade pode ser estabelecido como um dos atributos requeridos da peça que será projetada e/ou manufaturada. A pesquisa apresentou um modelo de informação que permite determinar a manufaturabilidade em paralelo com outras atividades de projeto.

Krishnan e Srihari (1995) demonstraram que os sistemas baseados no conhecimento podem ser aplicados nas funções do projeto orientado para a manufatura, melhorando o tempo cíclico do projeto. Descrevem, também, o projeto e desenvolvimento de um sistema especialista integrado baseado em um ambiente de projeto orientado para a manufatura de montagens de placas de circuito integrado. O sistema foi dividido em três componentes principais: (a) interface com o usuário; (b) um mecanismo de atualização junto com a máquina de inferência; (c) o banco de dados para gerenciamento.

Lenau (1996) descreve um método sistemático para seleção dos processos de manufatura e materiais durante os primeiros estágios do desenvolvimento do produto. Ele propôs três modelos de informação, chamados como modelo de processo, modelo de material, e modelo de produto. $\mathrm{O}$ modelo de processo descreve o tipo, a quantidade e o nível de detalhes que devem ser incluídos em cada processo, e descrições similares são providas para os modelos de material e produto. $\mathrm{O}$ modelo de processo inclui propriedades gerais relevantes ao projeto, como geometria, tolerâncias, qualida- de de superfície, bem como critérios de avaliação cobrindo problemas de confiabilidade, custo e ambiente.

Barton et al. (1996) descrevem uma arquitetura de banco de dados e uma metodologia estatística que formaliza o feedback da informação da manufaturabilidade para o projeto PCA, atualizando as regras de projeto baseadas nas experiências de manufatura. Propuseram a captura quantitativa das relações entre manufaturabilidade, produto e parâmetros do processo de projeto, usando estatística ou modelos de rede neural, criando atualizações de regras de projeto baseadas no modelo desenvolvido de manufaturabilidade.

\section{Modelos de Informação}

As indústrias, para se manterem competitivas, precisam mudar radicalmente suas estruturas organizacionais, e essas mudanças podem ser auxiliadas por computadores e softwares na integração entre o projeto do produto e sua manufatura. Sistemas dirigidos de dados reconhecem a importância da confiança, dividem informações e, portanto, tendem a ser implementados em torno dos modelos de informação, por exemplo, modelos de produto e modelos de manufatura, que podem cumprir todos os requerimentos de informações de diferentes aplicativos computacionais ligados ao sistema. Essas ferramentas (computadores e softwares) oferecem flexibilidade, integração de dados e apoio durante o ciclo de vida do produto. Elas devem também ser modulares e de fornecedores independentes (ELLIS et al., 1995). Modelos de sistemas de dados dirigidos (Data model driven systems) devem usar e gerar informações a partir de aplicações múltiplas de software de diferentes origens e mesmo assim manter a compatibilidade de dados entre os modelos de informação (YOUNG et al., 1998, 1999). Lee e Young (1998) exploraram o modelo dirigido de dados para projeto simultâneo de produtos e moldes de injeção de plástico. Eles definiram a funcionalidade e a estrutura de um conjunto de aplicativos para produtos e moldes de injeção de plástico que utiliza modelo de dados de produto e manufatura para aconselhar no processo de modelagem da moldabilidade da peça e no projeto do molde. Gorti et al. (1998) afirmaram que muitos pesquisadores focaram em representação de processos, por exemplo, eles mostraram as representações do processo versus a representação do produto. O processo de representação é baseado na decomposição funcional de cima para baixo (top-down) enquanto a representação do produto em termos de projeto é de baixo para cima (bottom-up).

A maior parte dos trabalhos de pesquisa examina a estrutura e o conteúdo do modelo de informação e em particular a modelagem do produto. Krause et al. (1993) apresentaram uma visão global do estado da arte e prática da modelagem do produto.

Modelos de Informação no suporte 


\section{ao Projeto Orientado para a Manufatura}

A injeção de plásticos é uma área importante da engenharia de produto, porque ela cobre muitas outras subáreas específicas. Essa área abriu oportunidades para pesquisadores explorarem problemas de múltiplos pontos de vista devido à diversidade e complexidade dos problemas relacionados com peças plásticas e suas modelagens de manufatura. Pratt et al. (1993) desenvolveu um conhecimento para o exame da manufaturabilidade e processabilidade das peças, mas a pesquisa ficou restrita ao projeto de peças plásticas. Weinten e Manoochehri (1996) apresentaram uma metodologia para definir somente a linha de partição do molde baseada na geometria da peça plástica. Lee et al. (1997) apresentaram uma metodologia sistemática, com base no conhecimento tecnológico de injeção de plástico, para projeto de produtos e moldes de injeção plástica em um ambiente de engenharia concorrente, não mostrando, todavia, como a geometria da peça plástica pode ser convertida para o projeto do molde.

Esta pesquisa está focada em três áreas relacionadas com produto e moldes para a injeção de plásticos: o projeto da peça plástica pelo projetista do produto, o projeto da cavidade do molde pelo projetista do molde é finalmente, a manufatura do molde pelo fabricante do molde. Nestas áreas existe um número específico de vistas que devem ser endereçadas a fim de resolver as interações existentes entre as diferentes vistas do produto, como ilustra a Figura 1. O trabalho concentra-se nas interações entre as vistas damoldabilidade, da cavidade do molde e da manufatura da cavidade do molde.

\section{METODOLOGIA DE DESENVOLVIMENTO}

Conforme Cervo e Bervian (2002), as pesquisas podem ser classificadas pela sua natureza, sua forma de abordagem, pelo caráter do objetivo e dos procedimentos técnicos. Quanto à sua natureza, este é um trabalho aplicado, isto é, tem os conhecimentos gerados aplicáveis em um problema prático. Quanto à forma de abordagem, pode-se classificar este trabalho como qualitativo, pois as avaliações e discussões são subjetivas e baseadas na interpretação dos fatos. No tocante ao objetivo, este pode ser classificado como exploratório, pois, a partir da exploração das diferentes vistas do produto no banco de dados Modelo de Produto (Product Model), pro-

Figura 1: Múltiplos pontos de vista em moldes e produtos plásticos injetáveis.

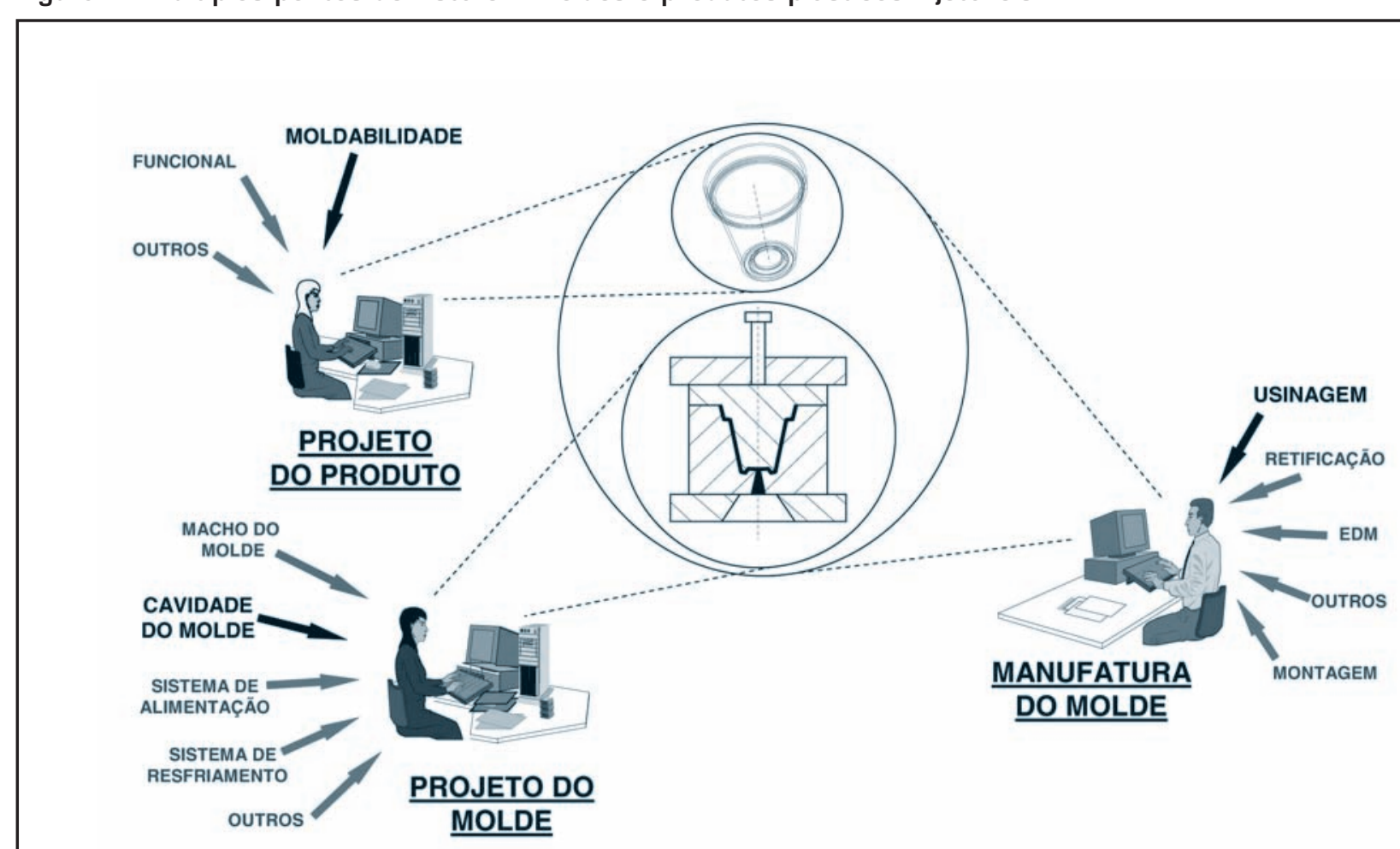


põe-se a integração destes. Em relação aos procedimentos técnicos, esta é uma pesquisa bibliográfica. Para o alcance do objetivo traçado, seguiram-se as seguintes etapas de desenvolvimento:

a) Determinação da abrangência da abordagem integrativa. Aqui, tomaram-se como linha de contorno da proposta três áreas de importância crucial às atividades de projeto orientado para a manufatura: o projeto da peça plástica, $\mathrm{o}$ projeto da cavidade do molde e a manufatura do molde.

b) Determinação dos métodos a serem integrados. Com vistas ao trabalho de integração entre as informações das vistas armazenadas no Modelo de Produto.

c) Identificação e análise da integração entre os métodos. Esta análise foi conduzida com base na lógica de conversão das informações existentes entre os requisitos necessários na entrada de cada vista e suas saídas. As interfaces são exploradas em partes para, em seguida, formular-se a integração completa entre os métodos destacados.

O artigo segue a estratégia de ordenamento da exposição de cada método segundo uma seqüência lógica de aplicação, partindo-se do projeto da peça plástica em direção à manufatura da cavidade do molde de injeção. Explora-se cada método de maneira sucinta. Conforme a conveniência de apresentação identificam-se, dentro dos tópicos, as interações existentes sempre entre duas vistas do projeto orientado.

\section{MODELO DE PRODUTO QUE CONTÉM INFORMAC̄ÕES DO PROJETO E DA MANUFATURA DO PRODUTO}

No futuro, Sistemas Computacionais de Projeto Orientado para Manufatura devem dar apoio para múltiplos processos, pois o projeto orientado para manufatura envolve considerações de várias diferentes perspectivas do produto, assim, é cada vez mais necessário equilibrar e integrar o trabalho com múltiplas vistas ou perspectivas do produto. Essa visão é apoiada pelo trabalho de Rosenman e Gero (1996), que explorou a abordagem de múltiplos pontos de vista em um projeto arquitetônico.

Uma das abordagens para projeto orientado para manufatura com múltiplas vistas é baseada no uso dos sistemas agentes (agent systems). Sistemas agentes têm sido definidos de maneiras diferentes pelos pesquisadores, mas a definição que melhor se encaixa neste contexto é "O sistema agente é visto como um sistema capaz de ação inteligente geral", ou é "um tipo de sistema de base de conhecimento" (WOOLDRIDGE; JENNINGS, 1995). Porém as comunicações ou transferências de informação entre diferentes domínios continuam causando problemas devido à diversidade de tipos de informações envolvidas em um ambiente de múltiplas vistas.

O desenvolvimento de aplicativos para projeto orientado para manufatura tem sido focado somente em pontos de vista da manufatura, de forma singular (GUPTA et al., 1997; KRAUSE et al., 1995; BOOTHROYD, 1994; FAUVEL, 1994). Por exemplo, Gupta et al. (1997) e Sanchez et al. (1997) abordam o projeto orientado para manufatura somente da perspectiva da usinagem, enquanto Boothroyd (1994) concentrou-se no projeto orientado para a montagem. A partir destes tipos de trabalho pode-se ver que cada vista requer sua própria estrutura de informações de produto. Ainda mais, que a estruturação das informações do produto é similar à estruturação explorada na área de tecnologia de features.

A Modelagem do Produto é outro importante aspecto da

\section{istemas de informação para o suporte as equipes de projeto.}

pesquisa envolvendo o desenvolvimento de sistemas CAE (Computer Aided Emgineering). Foi reconhecido tanto por pesquisadores como pelas comunidades que é necessário um sistema de informação avançado para integrar e coordenar várias considerações do ciclo de vida durante a realização do produto (KRAUSE et al., 1993). Por mais de duas décadas, a ISO (International Organization for Standardization) tem trabalhado no desenvolvimento do padrão STEP (Standard for The Exchange of Product model data), que é fortemente focado em intercâmbio de dados entre sistemas.

Isso também é importante para que os Modelos de Produtos, no futuro, sejam capazes de trabalhar com múltiplas vistas da representação do produto. Um importante aspecto da pesquisa dentro do sistema CAE de informação dirigida é, sobretudo, desenvolver modelos de produtos que possam capturar diferentes perspectivas do produto. Esse aumento da funcionabilidade do sistema pode ser atingido através do compartilhamento de informações relativas a representações dos diferentes aspectos do produto no modelo de produto (FOWLER, 1995). A comunidade STEP também reconheceu que existe a necessidade de compartilhar informações e integrar diferentes pontos de vista dos produtos, como evidenciado no trabalho do grupo WG10 (ISO TC184/SC4/ WG10 N219).

Pesquisas baseadas na modelagem do produto são tipicamente focadas na definição da estrutura da informação do produto, que conduzirá a uma aplicação particular. A Figura 2 representa conceitualmente a estrutura do Modelo do Produto que está sendo desenvolvida nessa pesquisa. A figura 
realça as três diferentes vistas que foram escolhidas para a exploração dos problemas/desafios existentes entre as vistas de projeto e manufatura do produto e do molde de injeção plástica. Elas têm a função de capturar informações específicas, incluindo a da descrição da modelagem de features para o projeto da peça plástica, do projeto do inserto da cavidade do molde e também da manufatura do inserto da cavidade do molde. Uma representação formal desta estrutura, isto é, de cada vista, foi criada usando a linguagem UML (Unified Modelling Language).

\section{Vista de Moldabilidade}

A vista de moldabilidade deve conter as informações sobre o produto plástico que será incorporado no projeto do molde, certificando-se que o molde poderá ser usado repetidamente para satisfazer as propriedades e outros requerimentos da engenharia do produto. Ela foi considerada como o ponto de partida para a exploração dos problemas na abordagem em múltiplas vistas e deverá conter toda informação relativa à sua moldabilidade. $\mathrm{O}$ exemplo usado para essa exploração pode ser visto na Figura 3. Contudo essa pesquisa não está preocupada com o modelagem de informação referente à moldabilidade do produto, uma vez que a informação da vista de moldabilidade já está guardada corretamente a partir do Modelo de Produto.
As features de moldabilidade são definidas como um conjunto de características para auxiliar a aplicação do projeto orientado para a moldabilidade. Essa sessão discute os tipos de features de moldabilidade usadas para modelar uma série de produtos prismáticos de paredes finas explorados nessa pesquisa.

Para iniciar a exploração do problema na vista de moldabilidade, primeiramente é necessário entender os tipos de features de moldabilidade apresentados na literatura, entender que informação e característica cada feature deverá conter e entender as relações entre eles. O ponto inicial desse trabalho de pesquisa foi a pesquisa desenvolvida por Lee (1996), que por sua vez foi baseada nas pesquisas desenvolvidas por Al-Ashaab, (1994); Cunnunghan e Dixon (1988); Dixon et al. (1990).

A abordagem dessa pesquisa é que a feature de Parede é considerada uma feature primária, porque o produto plástico, na maioria das vezes, é composto principalmente por paredes. Os reforços, como nervuras e ressaltos circulares, bem como os furos, só podem existir na parede e por essa razão foram classificados como features modificadoras. Isso leva à procura por novas informações taxonômicas, como mostradas na Figura 4. A figura ilustra a definição da taxonomia da moldabilidade prismática, que tem quatro subtipos de features que são: features Prismáticas Primárias;

Figura 2: Estrutura geral do Modelo de Produto (Product Model).

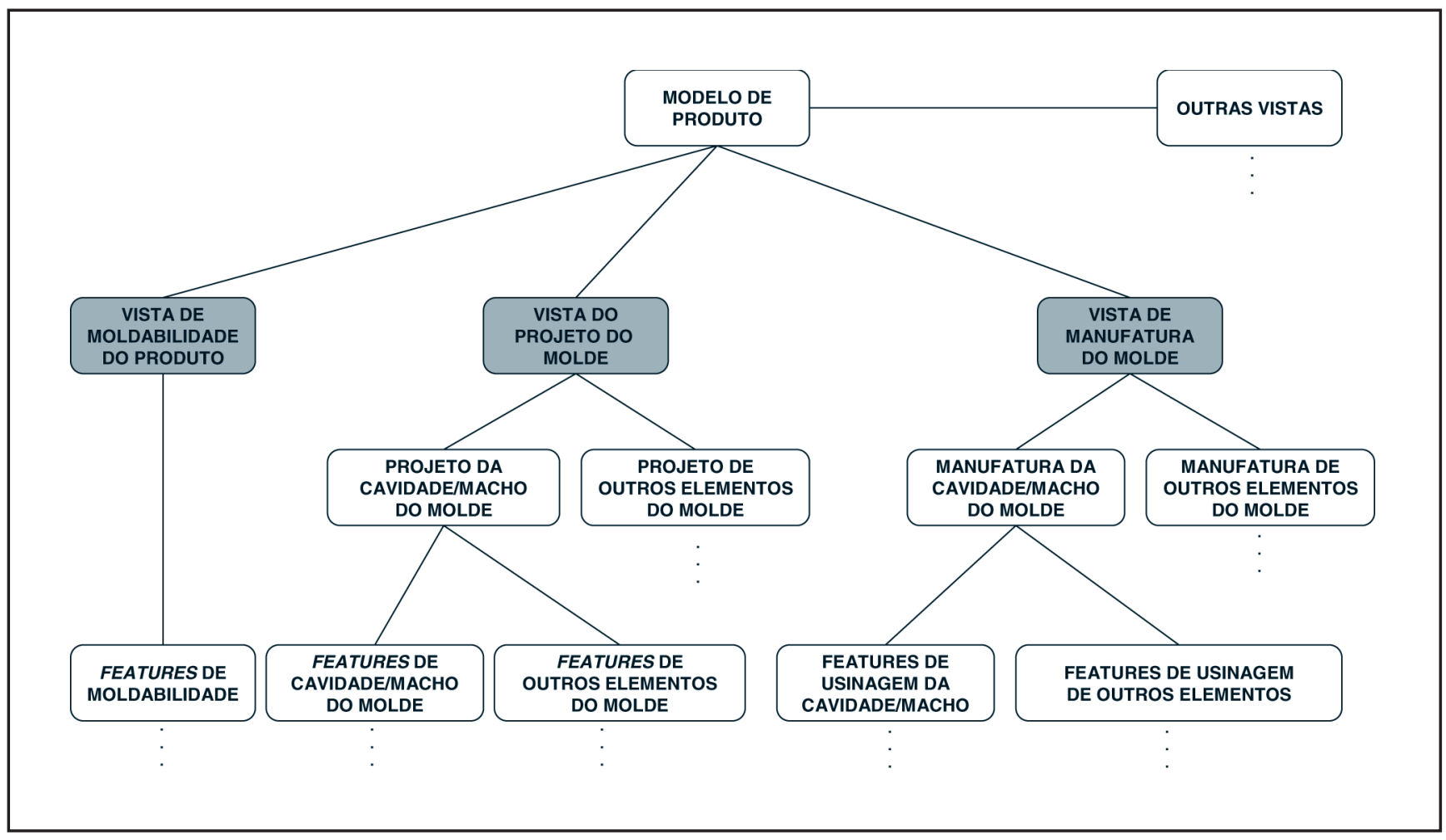


features Prismáticas Modificadoras; “features Prismáticas de Transição; e features Prismáticas de Linha de Partição do Molde".

A informação de moldabilidade deve auxiliar a aplica- ção do projeto para moldabilidade, que também auxilia o projeto do molde. Essa pesquisa não está preocupada em dar suporte para o projeto de moldabilidade, mas sim em explorar como as informações de moldabilidade podem ser

Figura 3: informação necessária na vista de moldabilidade de um produto prismático.
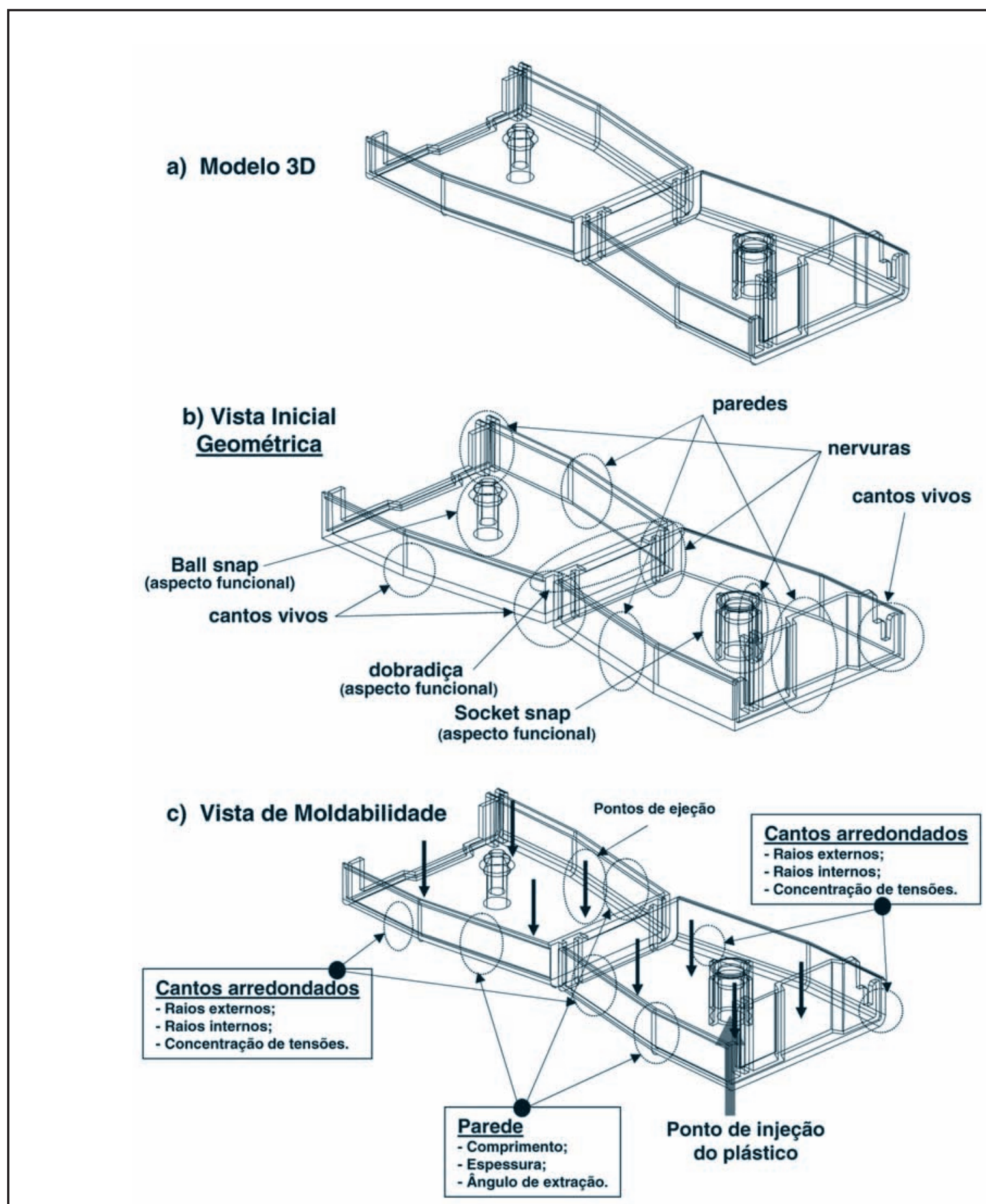
armazenadas corretamente no modelo do produto e pode dar suporte para outros aplicativos integrados num ambiente de múltiplas vistas do projeto e na manufatura. O significado e a terminologia utilizados nessa pesquisa, como paredes, reforços como nervuras, furos, entre outros, são visualmente ilustrados nos exemplos apresentados na Figura 3.

A estrutura hierárquica da classe da moldabilidade prismática está ilustrada na Figura 5. A figura apresenta as classes dessa estrutura: a classe de Moldabilidade prismática sendo a classe principal, e dividida em duas subclasses: a classe Produto Plástico Prismático e a Classe Considerações do Molde Prismático.

A classe do Produto Plástico Prismático é responsável por toda informação de moldabilidade relativa exclusivamente às peças plásticas e foi dividida em: Feature Prismática Primária; Features Prismáticas Modificadoras; e Features Prismáticas de Transição. Elas herdam toda informação a partir da classe principal do produto plástico. Já a classe Considerações do Molde Prismático é responsável por toda informação de moldabilidade do plástico a ser injetado em relação ao molde. Esta classe foi sub-dividida em: Features Prismática de Linha de Partição do Molde; Features do Ponto de Injeção do Plástico; e a Feature dos Pontos de Extração, que define os pontos de extração da peça plástica injetada do molde de injeção.

As Features Prismáticas Primárias são responsáveis pela criação da forma básica de um produtos plástico prismático (de paredes finas) em relação às restrições da moldabilidade do plástico que será injetado. Entre duas features primárias existe a necessidade de uma conexão e essa conexão pode ser obtida através de uma Feature Prismática de Transição que as conectará, de maneira correta e precisa, às superfícies internas e externas do produto plástico. Dessa forma a $\mathrm{Fe}$ - ature Prismáticas Primárias poderão agregar uma ou mais Features Prismáticas de Transição.

\section{Vista do Projeto da Cavidade do Molde}

A vista do projeto do molde é o segundo ponto para ser estudado numa abordagem exploratória de vistas múltiplas. Nela deve-se conter toda a informação relativa ao projeto da cavidade do molde de injeção, que pode ser dividido em sistemas como impressão, alimentação, extração, resfriamento, etc.. O molde de injeção de plástico pode ser padronizado em duas placas, moldes de cavidades bipartidas, moldes com cavidade dividida em mais de duas partes, entre outros. Nessa pesquisa somente serão consideradas a cavidade para o molde de duas placas e a informação relativa ao sistema impressão (cavitiy), a posição do bico de entrada e dos pontos de extração, como demonstrado na Figura 6.

Para manipular a informação existente no projeto de molde, primeiro é preciso entender quais informações são necessárias em cada estrutura de classe de projeto de molde, entender as relações existentes entre essas classes e como manipular a informação de maneira que coopere com suas interações. Essa informação não representa somente o projeto do inserto, mas também como ela será utilizada no auxílio da manufatura do inserto do molde (cavity insert). A figura ilustra também o sistema de impressão de um produto plástico prismático com seu furo para entrada do plástico liquido no processo de injeção (gate hole) e os furos de fixação e posicionamento do inserto.

O inserto de cavidade prismático (Pris_Cavity_Insert) é associado a uma feature prismática de linha de partição (Feat_Pris_Linha_Part_Molde) e pode agregar somente uma cavidade prismática (Pris_Cavity) como também

Figura 4: Taxonomia de features de moldabilidade prismática (Canciglieri, 1999).

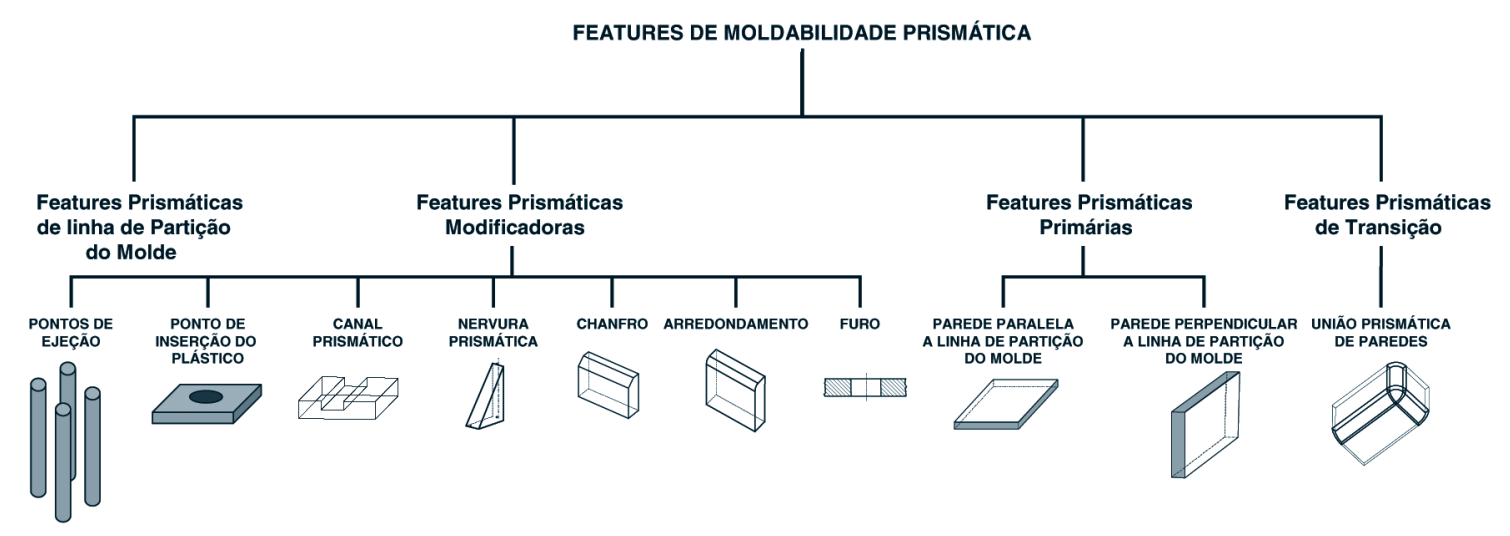


Figura 5: Estrutura de dados da Moldabilidade do Produto Prismático.

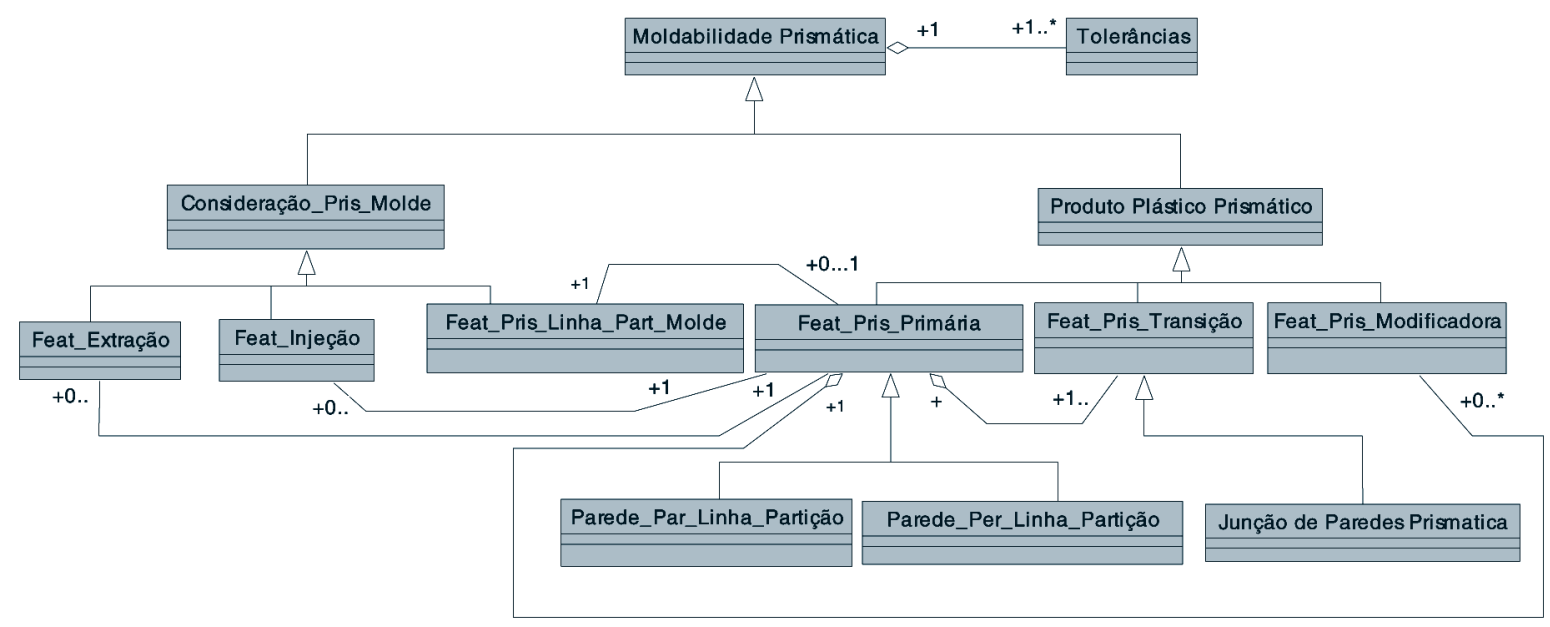

Figura 6: Sistema de Impressão (Insertos para o macho e a Cavidade do molde de injeção).

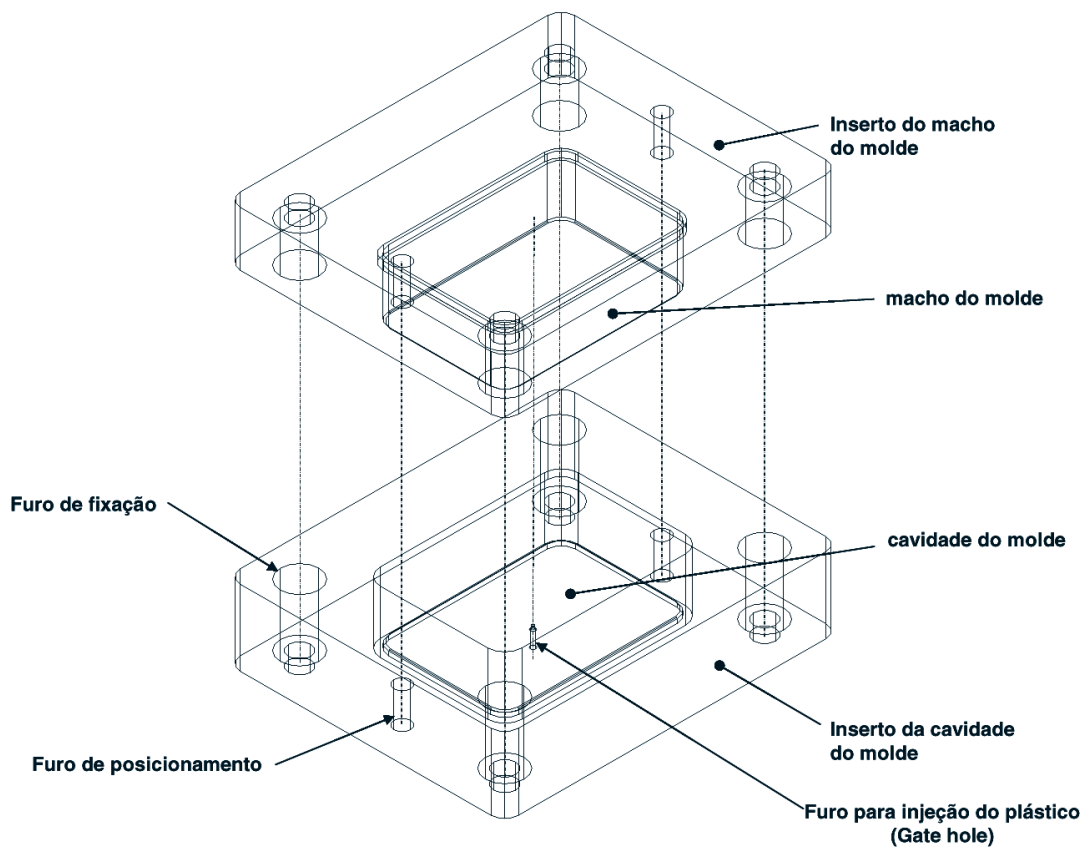


somente um inserto de cavidade no corpo principal (Pris Cav_Insert_Main_Body), como enfatizado na Figura 7. A figura ilustra, também, a cavidade prismática e o inserto de cavidade do corpo principal agregando uma ou mais superfícies geométricas individuais (Individual_Geometric Surface) que pode ser uma superfície plana (Plane_Surface) ou uma superfície curva (Curve_Surface), e cada superfície geométrica individual agregando uma ou mais tolerâncias.

\section{Vista da Manufatura da Cavidade do Molde}

A terceira vista explorada nessa pesquisa é da manufatura do molde, que contém todas as informações sobre o molde relativo a sua manufatura. Para se fazer o molde existem várias técnicas ou processos que podem ser empregados. Mesmo havendo várias maneiras de se fazer o molde, essa pesquisa se preocupa somente com os moldes usinados.

Um molde de injeção é a composição de vários sistemas, que requerem diferentes tipos de informação. Um desses sistemas é relativo à sua manufaturabilidade. Essa informação deve auxiliar o projetista através dos aplicativos a decidir qual processo ou processos são os mais adequados para a fabricação do molde. Nessa pesquisa foi enfocada somente a informação requerida para a manufatura do sistema de impressão (inserto da cavidade) e os furos a que pertencem esses insertos (furos de fixação, furos de posicionamento e bico de entrada no inserto de cavidade).

A informação geométrica do inserto de cavidade é muito importante, bem como cada feature de usinagem que será usada para manufaturar o inserto, pois elas são primariamente relacionadas à sua geometria. Essa geometria deve prover informações geométricas em termos de sua forma, que permitirá

Figura 7: Estrutura de dados do Projeto da Cavidade Prismática.

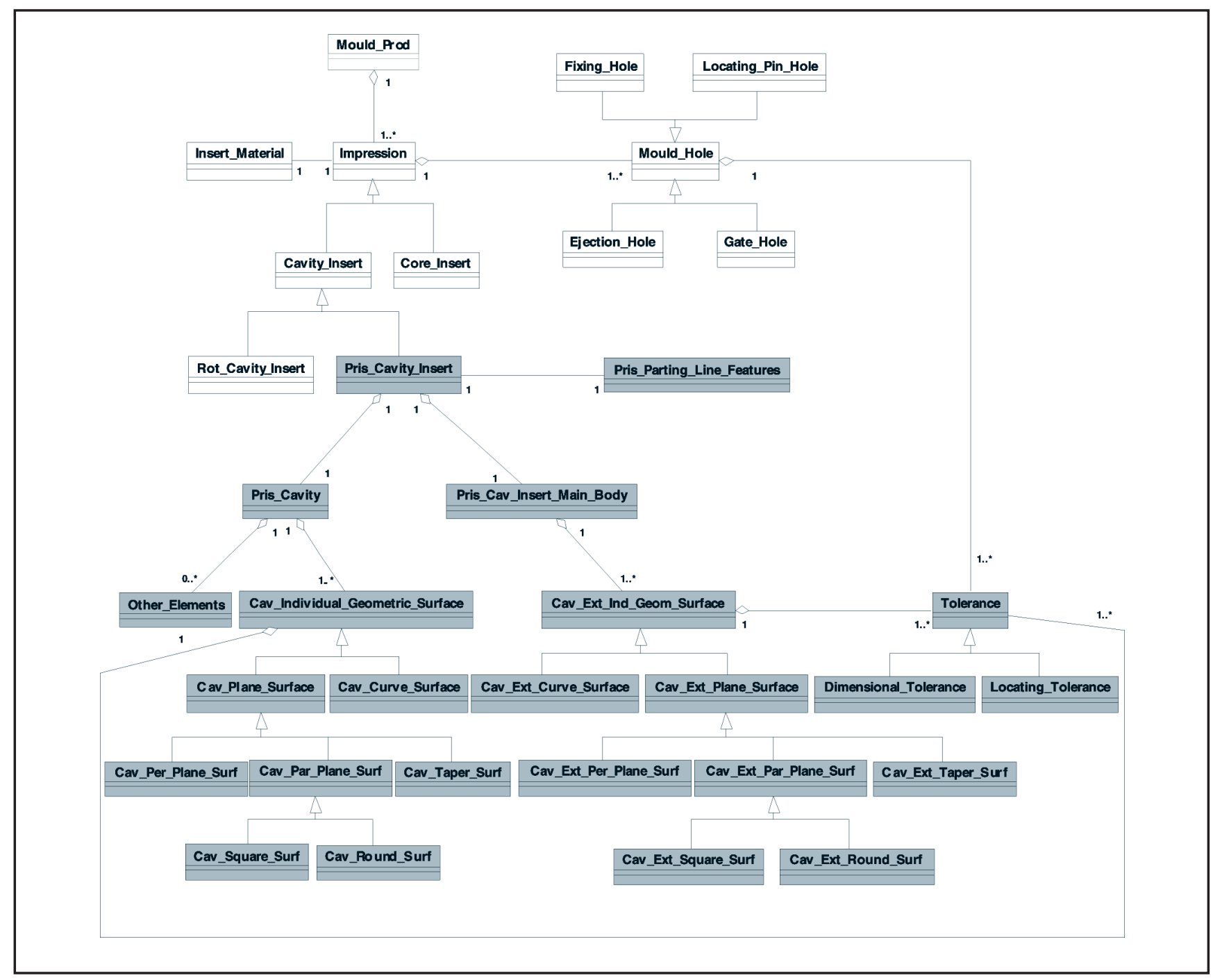


determinar o volume do sólido que será removido da matériaprima. A definição geométrica para o inserto de cavidade na vista de manufatura é dividida em duas categorias:

1. Informação geométrica da cavidade para a manufatura;

2. Informação do corpo principal do inserto de cavidade para a manufatura.

A definição da manufatura do inserto da cavidade está relacionada com a remoção do material da matéria-prima para produzir a forma do inserto da cavidade requerida. Dessa forma, a definição geométrica usada para a manufatura de inserto de cavidade é muito similar à definição geométrica apresentada para a vista do projeto de inserto da cavidade. A Figura 8 mostra um inserto de cavidade prismático, onde a figura "a" ilustra o sólido prismático de cavidade (prismatic cavity geometry) gerado pela união das superfícies planas e curvas. Nesse caso, também o sólido é considerado como volume negativo, uma vez que deve ser removido do material bruto. A Figura 10b apresenta a forma externa do inserto, a geometria do bico de entrada e dos furos de posicionamento e fixação. A forma externa ou corpo principal é considerada como volume positivo e a diferença de volume entre o material bruto e eles deve ser removido, sendo assim, os furos são considerados como volume negativo.

A informação de tolerância do molde é muito importante do ponto de vista da manufatura. Essa informação está relacionada com o acabamento superficial requerido para a cavidade, relacionado com os aspectos funcionais da peça plástica e com a facilidade de montagem de cada peça do molde. A informação de tolerância juntamente com a informação geométrica dará ao projetista, em conjunto com os aplicativos do projeto de manufatura, informações substan-

Figura 8: Vista da Manufatura de um inserto da cavidade prismática.

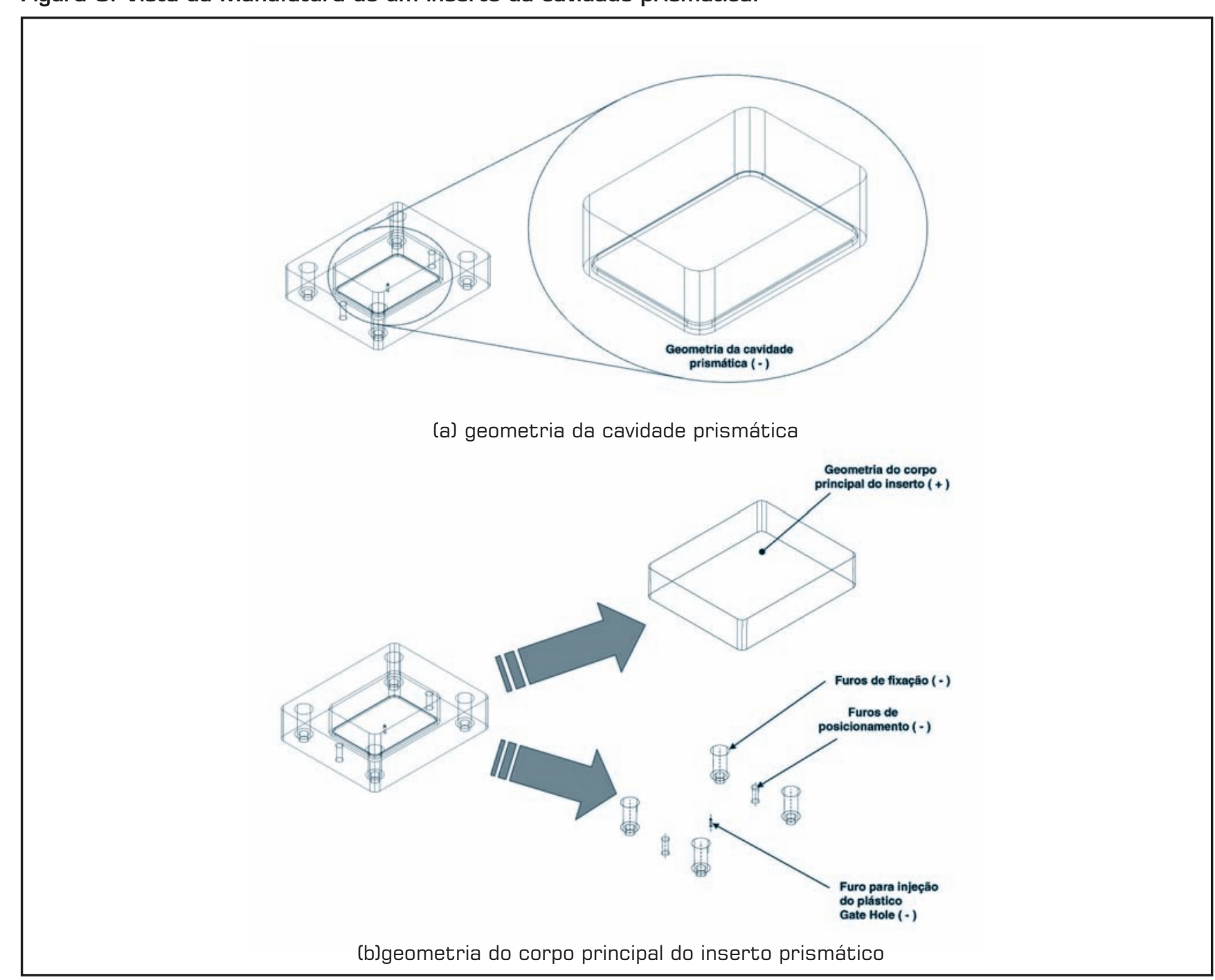


ciais para decidir qual processo ou processos poderão ser usados para manufaturar o inserto do molde. Essa parte da pesquisa na vista da manufatura do molde está concentrada somente em como definir as features de usinagem de maneira a produzir o inserto da cavidade do molde. Cada feature de usinagem está relacionada diretamente com a de tolerâncias, que nesse caso pode ser dimensional ou geométrica, como definidas na sessão anterior da vista de projeto do molde. As tolerâncias da cavidade vêm diretamente da peça plástica relacionada ao acabamento da superfície requerido para as superfícies internas e externas, sua dimensão de espessura, seus aspectos funcionais, como as dimensões das dobradiças plásticas, clips de conexão, entre outros. Outras tolerâncias, como o alinhamento dependem de cada parte do molde que será necessário ser montada com ele. A Figura 9 ilustra um caso onde o inserto do macho não está alinhado corretamente com o inserto da cavidade, e como resultado, dessa diferença de alinhamento de montagem, um lado do produto plástico terá uma parede muito fina enquanto que o outro uma parede muito grossa.

Assim, a informação de tolerância é fundamental para a vista de manufatura, porque suas informações estão relacionadas diretamente a cada tipo de processo, contudo somente a tolerância não é suficiente para definir o processo de manufatura. A definição geométrica das peças a serem manufaturadas também é necessária.

A classe hierárquica da manufatura do molde, definida pelos autores de maneira a auxiliar os aplicativos da manufatura do molde usando a abordagem das vistas múltiplas em projeto e manufatura, está apresentada na Figura 10. A figura ilustra a estrutura principal das classes Mould_Prod_Manufacturing e Impression_Manufacturing, que são as classes raiz (parent class). A relação entre elas é que o Mould_Prod_Manufacturing agrega um ou mais objetos da classe "Impression_Manufacturing, podendo pertencer a um único inserto de cavidade que será manufaturado. Elas podem ser rotacionais para a superfície de revolução ou prismáticas para superfícies planas ou curvas. A classe da manufatura do inserto está associada com o material do inserto (Insert Material). A manufatura dos objetos dos insertos de cavidade agregam um ou mais diferentes tipos de furos que serão manufaturados (Mould_Hole_Manufacturing) e cada classe de inserto agrega uma ou mais features de usinagem.

A cavidade que será manufaturada pode ser rotacional ou prismática de acordo com a forma do produto plástico. A Figura 11 enfatiza a estrutura de dados da manufatura de inserto de cavidade prismática. Cada classe de manufatura do inserto da cavidade prismática (Pris_Cav_Insert_Manufacturing) agrega uma única manufatura da cavidade (Pris_Cavity_Manufacturing), uma única manufatura do corpo principal do inserto de cavidade (Pris_Cav_Insert_Main_Body_Manufacturing) e um ou mais furos para a manufatura (Mould_hole_Manufacturing). Essa três classes agregam uma ou mais features de usinagem, isso significa que cada um deles pode ser usado por um ou mais tipos de processos de usinagem de maneira a manufaturar a geometria requerida de acordo com a tolerância especificada pelo projetista.

A estrutura de classe do inserto macho prismático tem

Figura 9: Exemplo de problema com a tolerância de alinhamento de montagem.

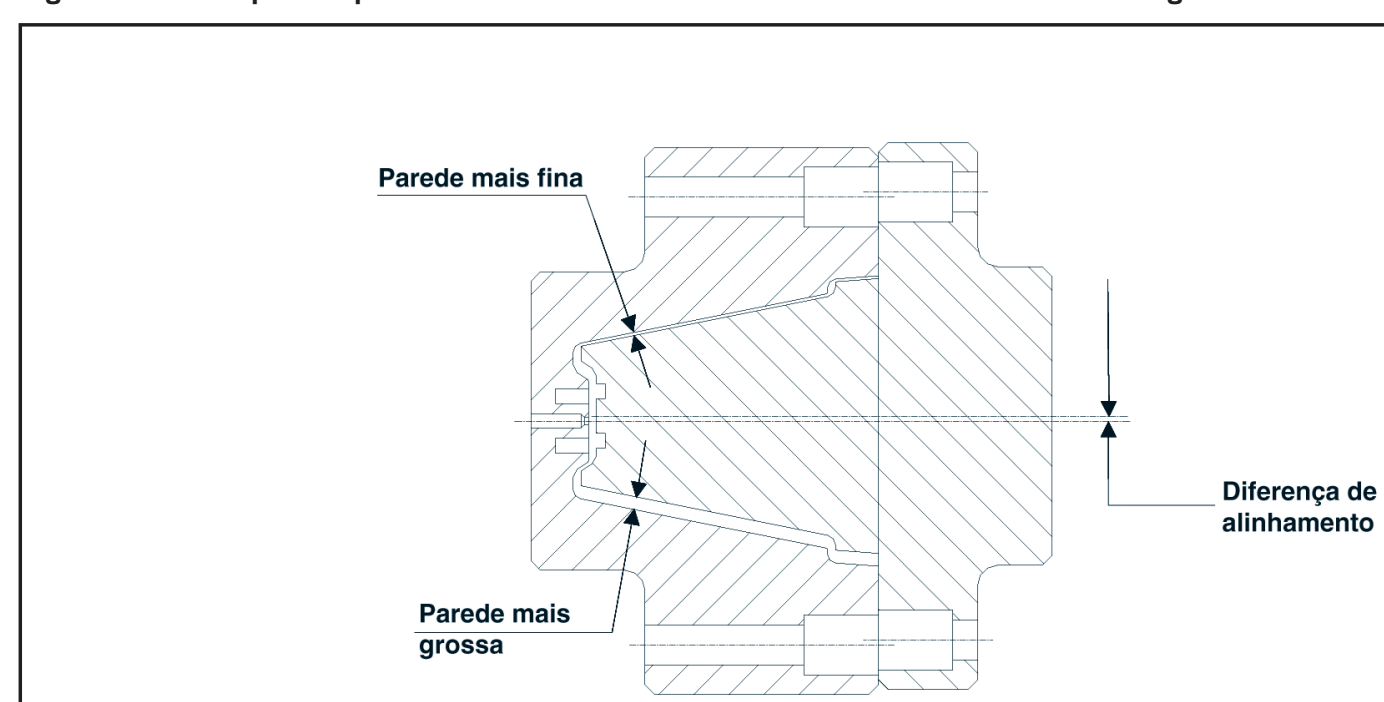


uma estrutura de classe similar à da cavidade prismática e as relações entre as classes são também similares. Em termos de manufatura da parte externa do inserto e os furos, as estruturas de classe são as mesmas com nomes distintos. Contudo, para a manufatura do inserto macho (core protrusion) a estrutura de dados é bem diferente, já que deve ser considerado como geometria positiva, o excesso de material deve ser removido do material bruto antes que atinja a geometria desejada do macho do molde, enquanto que para a manufatura da cavidade prismática o processo oposto deve ser aplicado.

\section{IMPLEMENTAC̣̃̃O DO MODELO DE PRODUTO NUM AMBIENTE DE MÚLTIPLAS VISTAS}

Esta seção apresenta a implementação do modelo de produto através das vistas de moldabilidade, do projeto da cavidade e da manufatura da cavidade em um banco de dados orientado ao objeto UNISQL. As vistas foram implementadas de acordo com as definições exploradas na seção anterior. Elas produzem dados de saída (outputs) e geram outras informações. Conseqüentemente, é necessário espaço suficiente em disco para o armazenamento das informações essenciais.

As estruturas de classes foram definidas eficientemente e devem ser guardadas de forma correta no banco de dados (Modelo de Produto), uma vez que o objetivo desta pesquisa não é desenvolver todos os aplicativos de projeto, mas provar que as informações oferecem suporte a uma quantidade de aplicativos usados nas atividades de projeto que focam a abordagem de múltiplas vistas em um projeto orientado para a manufatura de produtos plásticos injetáveis.

Cada classe foi definida em termos de seus atributos e

\section{A s indústrias precisam mudar radicalmente suas estruturas organizacionais. Essas} mudanças podem ser auxiliadas por computadores e softwares para integrar o projeto do produto a sua manufatura através das organizações.

suas associações com outras classes. Os atributos representam a identificação da classe (nome, descrição, etc.) e as informações tecnológicas (geometria, como as coordenadas dos pontos, linhas, planos, etc.). As associações representam os relacionamentos com outras classes, como, por exemplo, uma feature de moldabilidade (mouldability feature) pode conter nenhuma ou muitas features de modificação (mouldability modifying features) ou pode ser associada com uma tolerância específica ou superfície final.

A informação geométrica deve ser gerada por um sistema CAD integrado com um aplicativo, todavia, o desenvolvimento de uma interface com um sistema CAD não é parte do escopo desta pesquisa e é assumido que as informações devem ser geradas num sistema integrado. A implementação da vista de moldabilidade foi baseada nas features prismáticas de moldabilidade, que foram conceitualmente representadas previamente por diagramas de classe do UML. A Figura 12 ilustra em detalhes um exemplo da estrutura de classe de

Figura 10: Estrutura de dados da manufatura do molde.

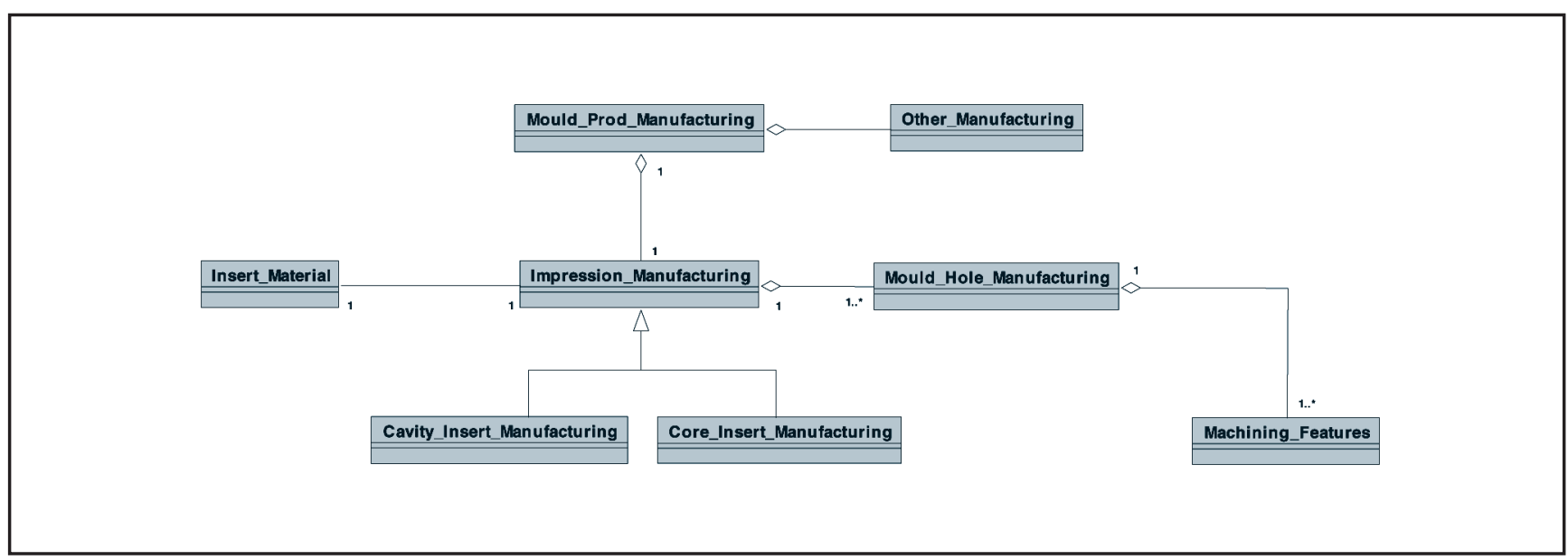


uma features de moldabilidade prismática (Prismatic_Mouldability_Feature).

A declaração de cada classe foi escrita num arquivo chamado top_level_9.h e second_level_9.h. A Figura 12 ilustra também a estrutura de cada classe, que foi dividida em 4 regiões (A, B, C e D). A região A é utilizada para definir o tipo de classe, isto é, se é principal (raiz) ou descendente de outra classe. A região $\mathrm{B}$ é utilizada para definir os atributos da classe (nome, descrição, número de identificação, etc.) e o valores dados a estes atributos definem o estado particular dos objetos. A região C é usada para definir os tipos de relacionamento entre esta classe e outras que são associadas, por exemplo, no topo da região C existe uma associação entre a classe features prismática de moldabilidade (Prismatic Mouldability Feature) e a classe da features prismática do produto consumidor (PRIS_CONS_PROD). Qualquer features de moldabilidade pode somente pertencer a uma features do produto enquanto que cada "features" do produto, pode conter uma ou muitas "features" de moldabilidade. Finalmente, a região "D" é usada para declarar as funções- membro que são chamadas em diferentes instâncias durante a execução do sistema.

A implementação das vistas do projeto e da manufatura do molde foi baseada nos mesmos princípios utilizados para implementação da vista de moldabilidade.

$\mathrm{O}$ produto plástico selecionado para o teste das vistas implementadas no modelo de produto está ilustrado no topo da Figura 13. O produto é uma caixa plástica prismática com um degrau no topo das paredes verticais. Este degrau tem a função de ajustar a tampa da caixa corretamente. A figura apresenta também as janelas de diálogos do banco de dados modelo de produto, que possui as informações referentes a este produto plástico. A janela A mostra o primeiro nível de representação do produto e seus atributos (nome, identificação e descrição) e as classes material do produto plástico (CONS_PROD_MATERIAL) e as features de moldabilidade (Pris_Mouldability_Feature) que estão associadas a este. A janela $B$ ilustra a informação do plástico em que a caixa prismática deverá ser produzida, que neste caso será o $\mathrm{PE}$ e seu coeficiente de contração térmica de 0,0325 . A janela C mostra a lista de features prismáticas de moldabilidade que pertence a este produto. Conceitualmente, os produtos plásticos prismáticos são definidos por superfícies planas e

Figura 11: Estrutura de dados de manufatura da cavidade prismática.

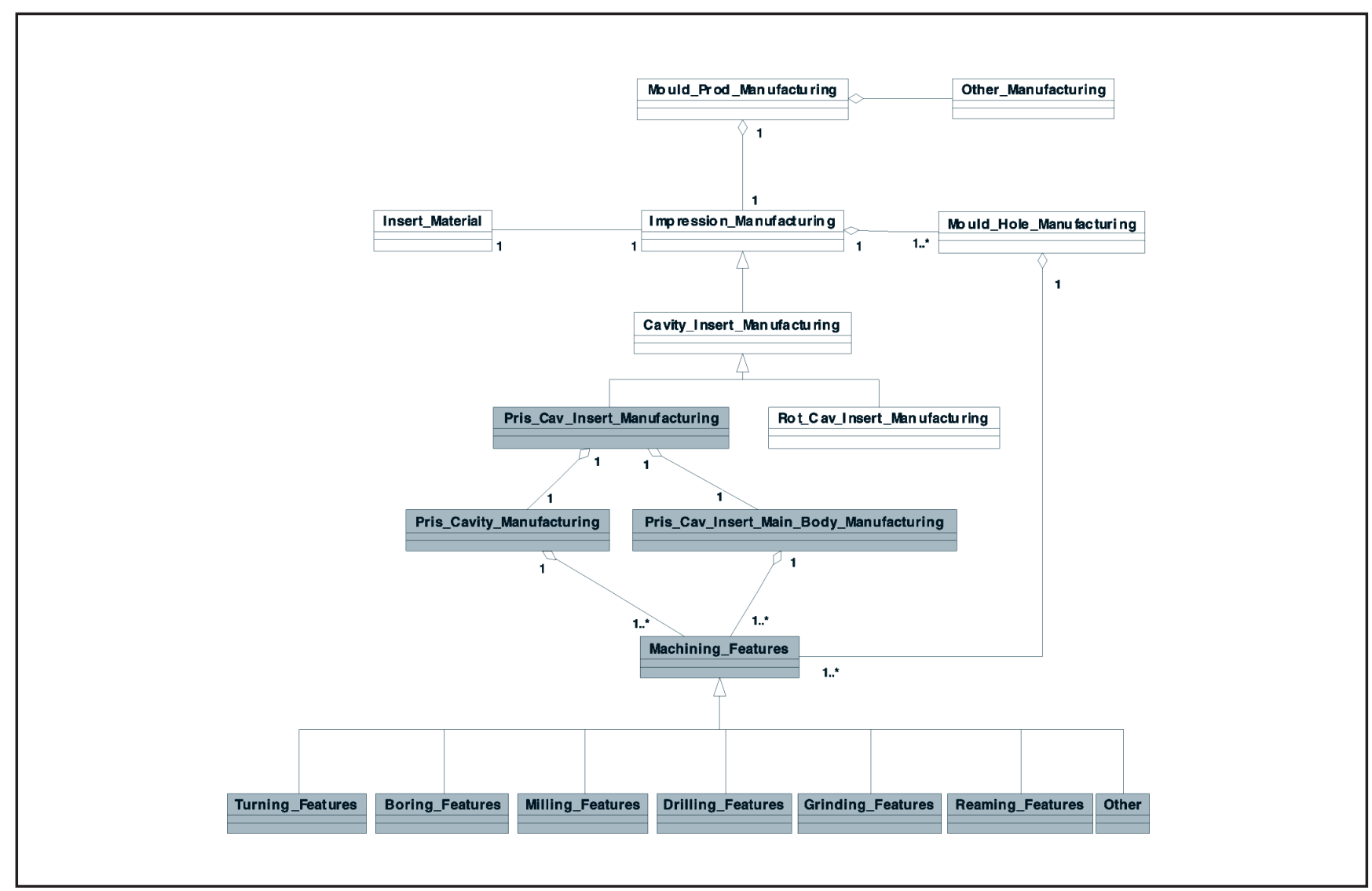


curvas (plane surface e curved surface).

$\mathrm{O}$ inserto da cavidade é composto de: uma cavidade prismática (Pris_cavity); um corpo principal do inserto (Pris_cavity_main_body), furos de fixação (fixing holes), furos de posicionamento (locating-pin holes) e o furo para inserção do plástico (gate holes) durante o processo de injeção, como ilustrado na Figura 14. A figura apresenta as janelas $\mathrm{A}, \mathrm{B}$ e C de diálogos do banco de dados que definem conceitualmente este inserto.

A figura 15 apresenta as janelas de diálogos, do banco de dados modelo de produto, que representam os dados da definição do inserto da cavidade prismática. A janela A ilustra o nome dado ao inserto, que é cavity2_mould2. O diálogo B mostra a lista de todos os furos pertencentes a este inserto. $\mathrm{O}$ inserto possui quatro furos de fixação com alojamento para a cabeça de parafuso (fixing holes), dois furos para o posiciona- mento do inserto no prato do molde (locating-pin holes) e um furo utilizado para entrada do plástico no processo de injeção (gate hole). A janela C ilustra a informação tecnológica de um dos furos de fixação (pris_cav_prod2_fix_hole 3) que deve ter um diâmetro de 8 milímetros, profundidade de $27,715 \mathrm{~mm}$, diâmetro e profundidade do alojamento de $12 \mathrm{~mm}$ e de $15 \mathrm{~mm}$ respectivamente. A janela D apresenta o material em que o inserto será feito. As janelas E, F e G ilustram as informações do inserto do corpo principal (cav main body prod2) e seus objetos associados. Já as janelas $\mathrm{H}$ e I mostram em detalhes a cavidade prismática (pris_cav_prod2) e seus objetos associados, que neste caso é a lista de superfícies (list_of_surf), sendo que esta lista é o resultado da conversão de informação feita pelos mecanismos de conversão, os quais serão objetos de exploração de um outro artigo.

A Figura 16 ilustra as janelas de diálogo que repre-

Figura 12: Feature prismática de moldabilidade (Prismatic mouldability feature).

\#ifndef_PRIS_MOULDABILITY_FEATURE

\#define_PRIS_MOULDABILITY_FEATURE

class PRIS_MOULDABILITY_FEATURE: public MOULDABILITY_FEATURE

\{

public:

II Attributes

odb_String name;

odb_String class_name;

int id;

odb_String description;

odb_Ref<AXIS> an_associated_axis;

odb_List<odb_Ref< POINTJ > > list_of_points;

odb_Ref $<$ PLANE> an_assoc_plane;

odb_Ref<PRIS_CONS_PROD> assoc_object inverse PRIS_CONS_PROD::list_of_obj;

odb_List< odb_Ref<PRIS_MOULDABILITY_FEATURE> > list_of_obj inverse PRIS_MOULDABILITY_FEATURE::assoc_feat;

odb_Ref<PRIS_MOULDABILITY_FEATURE> assoc_feat inverse PRIS_MOULDABILITY_FEATURE::list_of_obj;

odb_List<odb_Ref $<$ TECHNOLOGICAL_INFORMATION > > tec_inf_list;

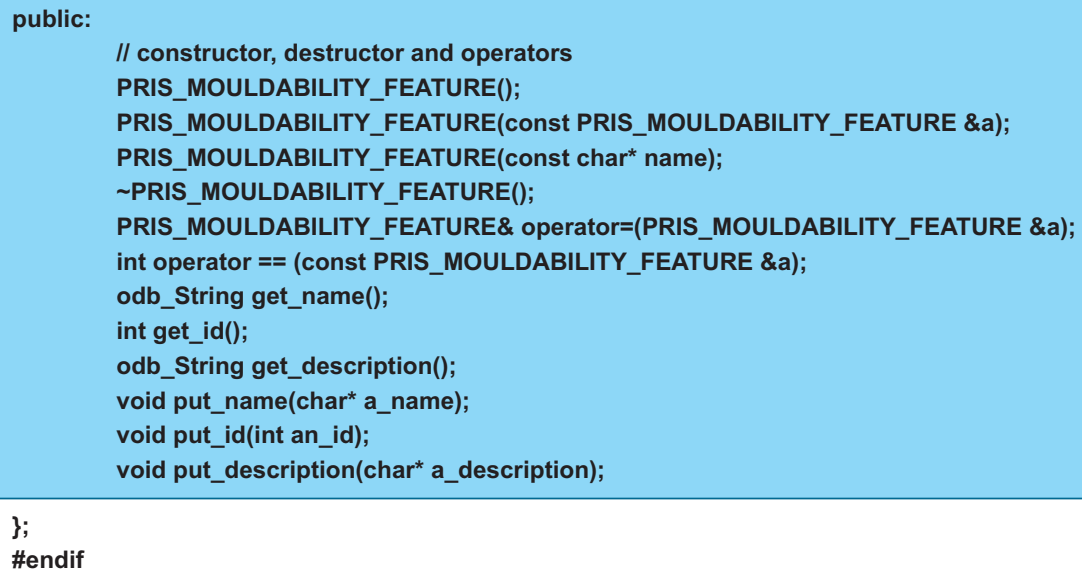


Figura 13: Representação da peça plástica prismática no banco de dados modelo de produto.

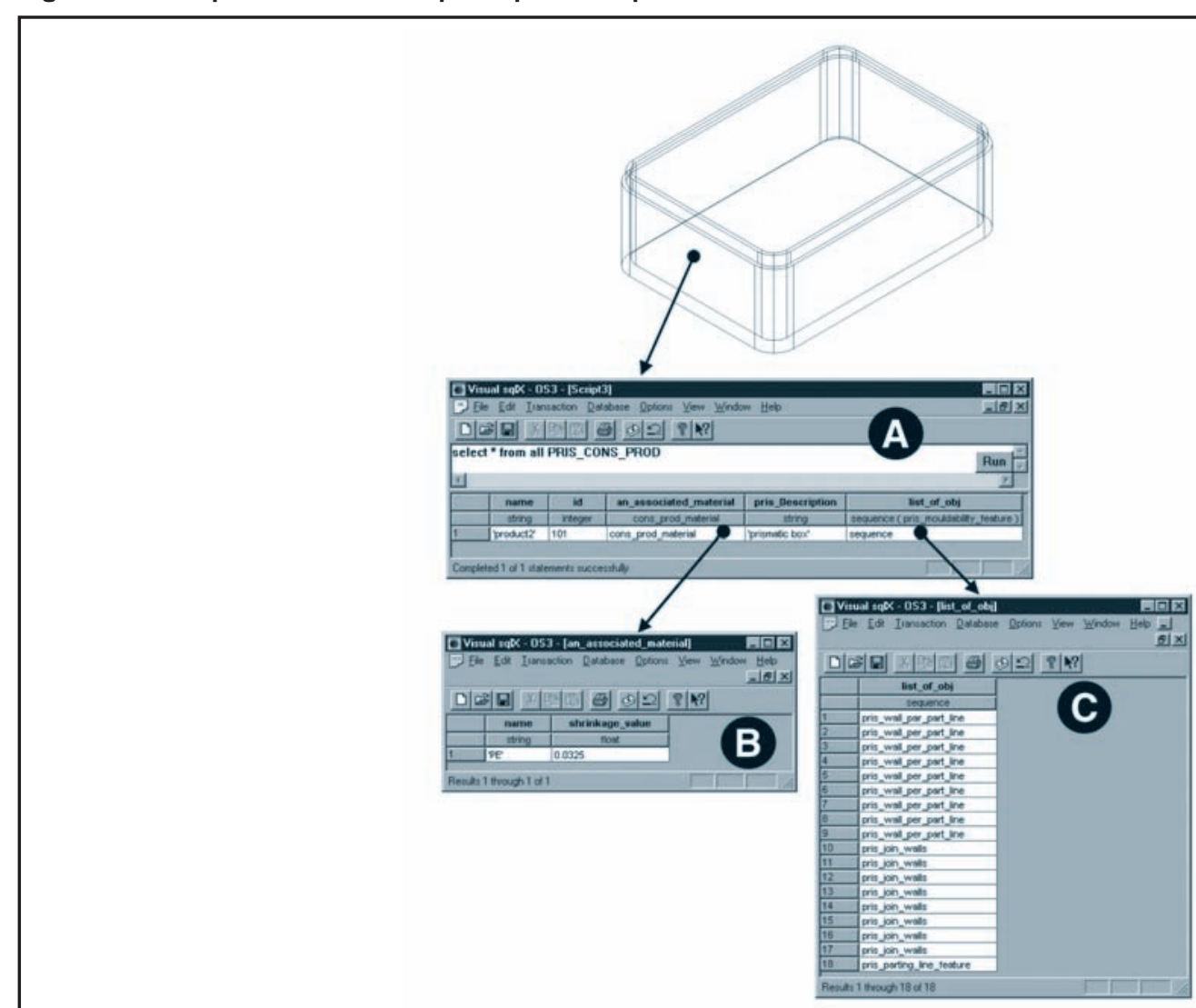

Figura 14: Representação do inserto da cavidade no banco de dados modelo de produto.

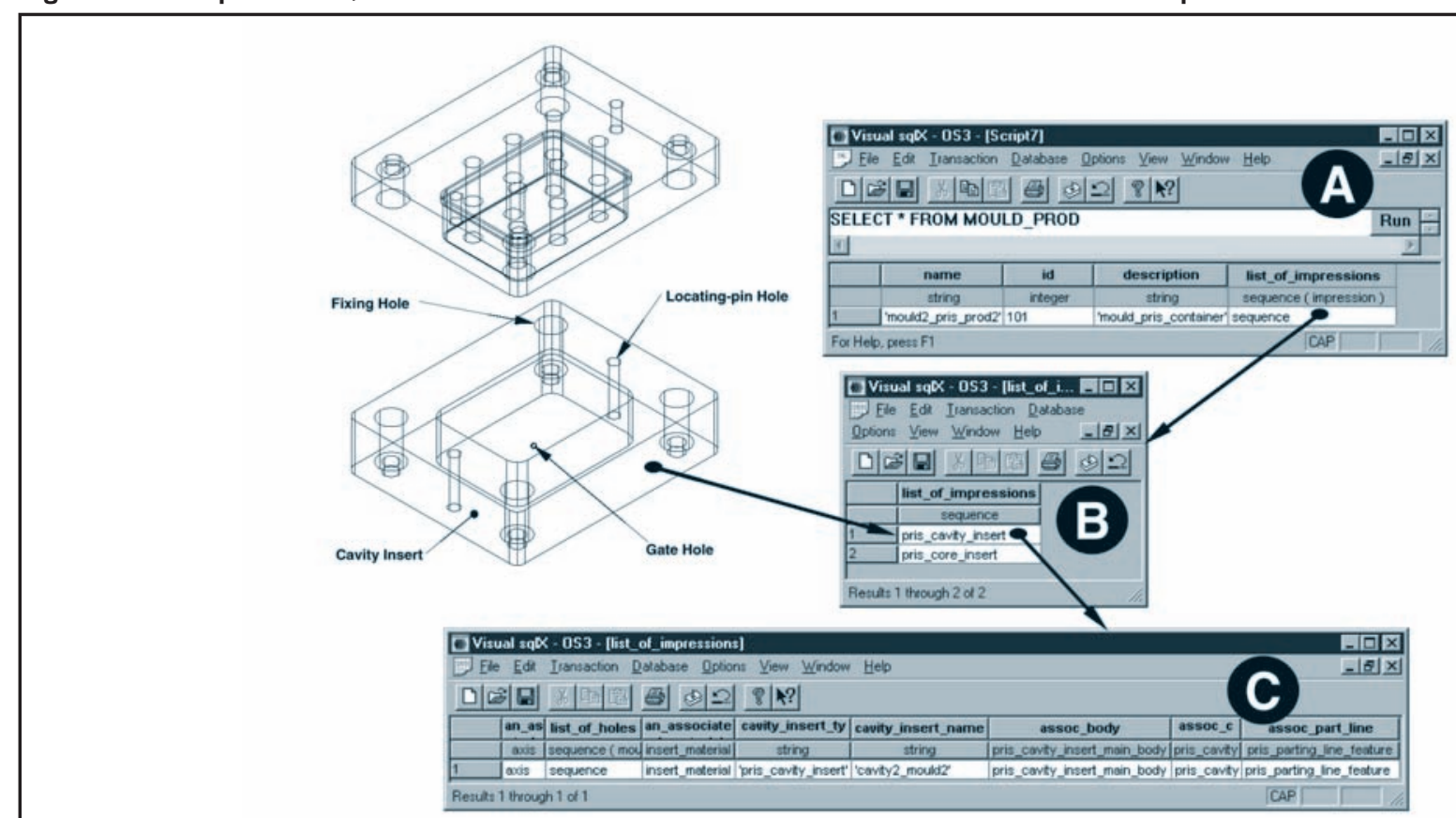


sentam a definição dos dados da manufatura da cavidade prismática, como ilustrado no diálogo $\mathrm{A}$ (pris_cav_manufacturing). $\mathrm{O}$ diálogo $\mathrm{B}$ mostra a lista de superfícies que deverão ser usinadas, o diálogo $\mathrm{C}$ os detalhes da features de superfície (lat_plane_surf_milling), o diálogo D os detalhes da features de superfície (top_plane_surf_milling) e o diálogo E também a features de superfície (lat_curve_surf_milling).

CONCLUSÃO E DISCUSSÃO
Esse artigo apresentou a necessidade de desenvolvimento de futuros sistemas de projeto de produto que deverão oferecer ferramentas para o suporte nas atividades de projeto em múltiplos pontos de vista do produto para as equipes. As vantagens de utilizar a abordagem de modelagem de informações e de prover um banco de dados de informações na forma de modelos de produto e manufatura como precursores para decisões sobre múltiplas vistas foram

Figura 15 : Representação do projeto da cavidade prismática.

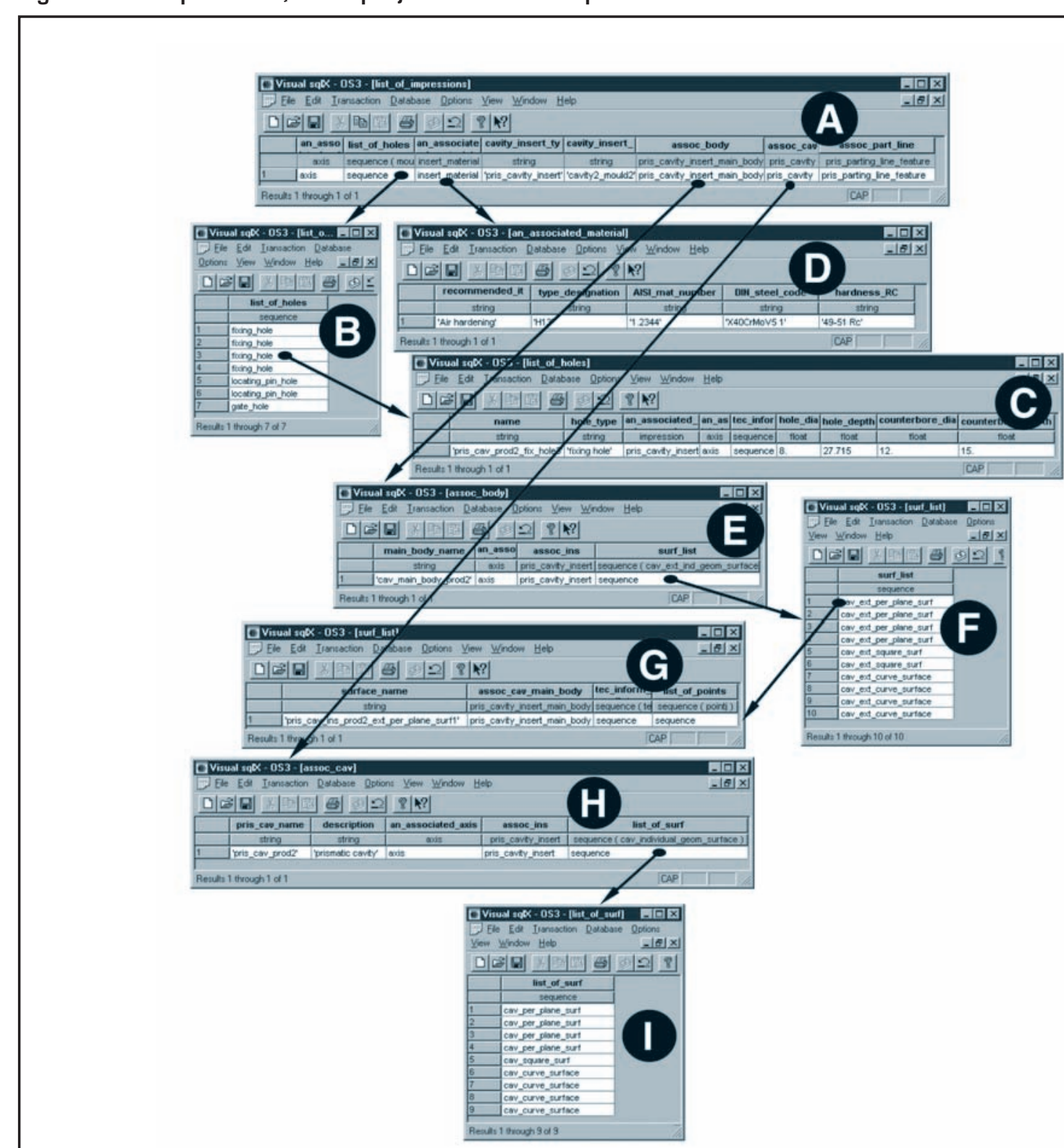


aqui enfatizados.

A estrutura de informação deve ser correta para auxiliar cada vista e ainda ser correlacionadas umas com as outras. A informação requerida para um caso em uma vista será a mesma requerida por outra vista. Nessa situação, as informações podem ser compartilhadas diretamente, ou em outros casos a informação de uma vista será relacionada com a informação em outra vista, mas não poderão ser compartilhadas diretamente. Por exemplo, a features da moldabilidade de uma parede tem relação com o molde da cavidade, que pode ser definida utilizando o mecanismo de conversão. Em essência, cada informação deve ser bem estruturada, de maneira a atender os dois casos. A abordagem de vistas múltiplas deve assegurar a consistência das informações atingidas e mantidas através de várias representações.

O nível de detalhe capturado na estrutura de informação é muito importante para que se determine a quantidade de processos que serão necessários para executar a conversão de informação de uma vista para a outra. Nessa pesquisa a classe descendente foi definida como o mais baixo nível possível para minimizar a complexidade do mecanismo de tradução. Essa abordagem facilita o compartilhamento e a tradução das informações entre vistas. Quando um número de vistas relacionado é incluído no sistema, estruturas de informações detalhadas são requeridas para certificar que toda possibilidade de tradução será coberta.

A pesquisa explorou definições de uma estrutura de dados específica para atender aplicações específicas. Ao mesmo tempo em que se mostrou adequada para a área focada, quando o conceito é estendido para a manipulação de um grande número de aplicativos, será preciso mais estudos a respeito da conversão de informação. Quando isso ocorrer, a abordagem deverá assumir que um grande número de definições de estrutura de dados será requerido. Isto tem potencial para conduzir a um nível de confusão nas definições das vistas do produto, a menos que um método de classificação de informação apropriado possa ser definido ou identificado.

Figura 16: Representação da usinagem de uma cavidade prismática.

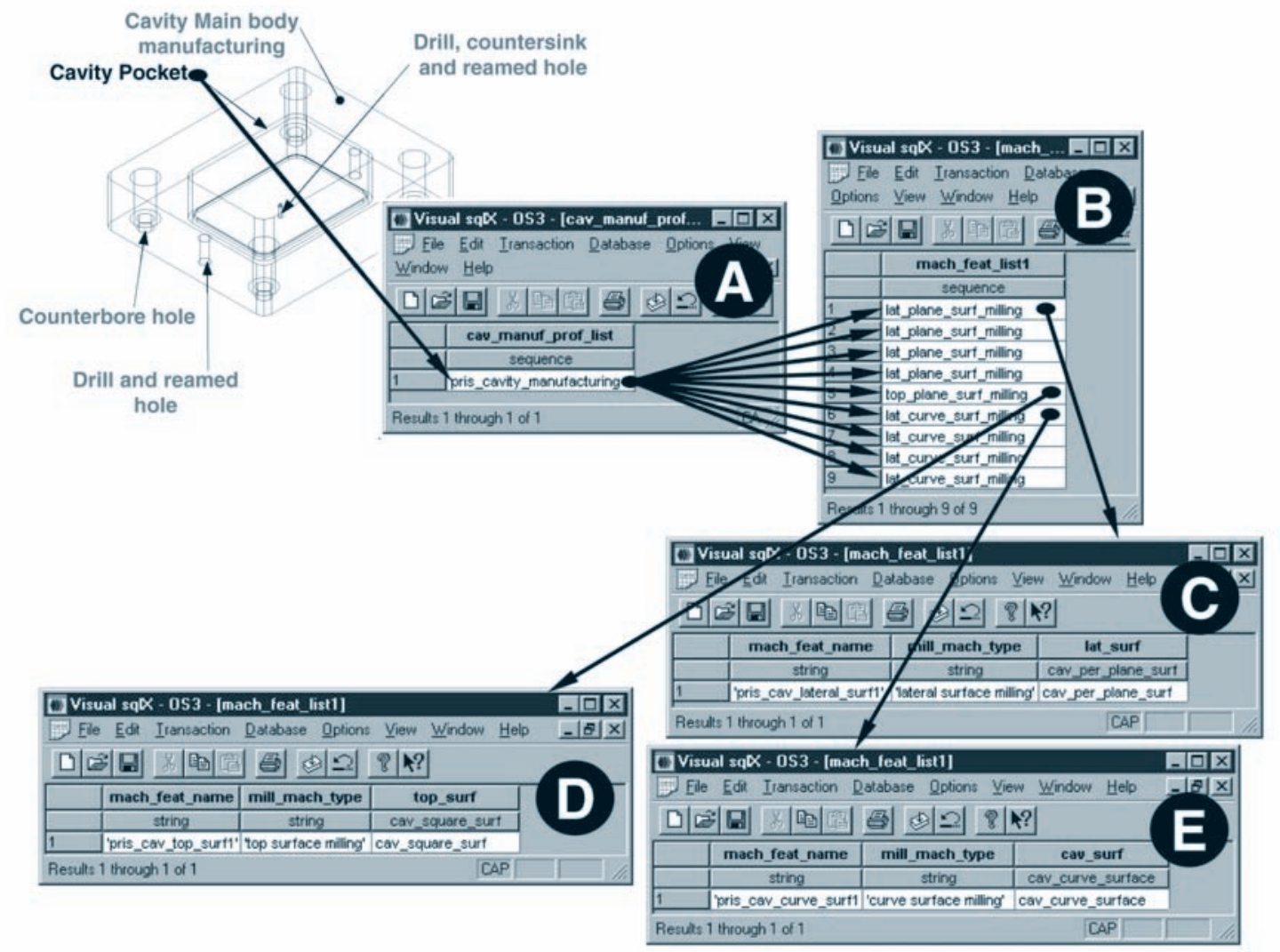




\title{
Artigo recebido em 11/06/2005 Aprovado para publicação em 05/05/2006
}

\author{
- Referências Bibliográficas
}

AL-ASHAAB, A. A manufacturing model to capture injection moulding process capabilities to support design for manufacture. PhD thesis, Loughborough University, 1994, UK.

ALLADA, V.; ANAND, S. Feature-based modelling approaches for integrated manufacturing: state-of-art and future research directions. International Journal Computer Integrated Manufacturing, 8, p. 411-440, 1995.

BARTON, R. R.; JOO, Y.; HAM, I. Feedback of manufacturing experience for DFM design rules. Annals of the CIRP, v. 45/1, p. $115-120,1996$.

BOOTHROYD, G.; DEWHURST, P. Product Design for Assembly. (Wake.eld), UK, 1990.

BOOTHROYD, G.; DEWHURST, P.; KNIGHT, W. Product Design for Manufacture and Assembly. New York: Marcel Dekker, 1993.

CANCIGLIERI, O. J. Product model based translation mechanism to support multiple viewpoints in design for manufacture of injection moulded products. $\mathrm{PhD}$ thesis, Loughborough University, 1999, UK.

CANCIGLIERI, O. J.; YOUNG, R. I. M. A multi-viewpoint reasoning system in design for injection moulding. In $\mathrm{M}$. AKKOK; ARIKAN, M. A. S.; BALKAN,T.; DARENDELILER, H.; GOKLER, M. I. and KAFTANOGLU (eds). Proceedings of the International Conference and Exhibition on Design and Production of Dies and Molds. Istanbul: CIRP, 1977, p. 21-26.

CANCIGLIERI, O. J.; COELHO, L. S.; YOUNG, R. I. M. Orientação a Objeto no Suporte de Projetos Orientados para a Manufatura, Revista Máquinas e Metais, Aranda Editora, v. 430, p. 160-173, 2001.

CANCIGLIERI, O. J.; YOUNG, R. I. M. Information Sharing in Multiviewpoint Injection Moulding Design and Manufacturing. International Journal of Production Research, Inglaterra, v. 41 , n. 7 , p. 1565 1586, 2003.

CERVO, A. L.; BERVIAN, P. A. Metodologia científica. 5. ed. São Paulo: Prentice Hall, 2002.
CHEN, P. C. L.; LECLAIR, S. R. Integration of design and manufacturing: solving setup generation and feature sequencing using an unsupervised-learning approach. Computer Aided Design, 26(1), p. 59-75, 1994.

COBERTT, J. Design for Economic Manufacture. Annals CIRP, v. 35/1, 1986.

CUNNUNGHAM, J.; DIXON, J. Designing with features: the origin of features Proceedings of ASME Computers in Engineering Conference, San Francisco, CA, p. 237-243, 1988.

CUTKOSKY, M. R.; BROWN, D. R.; TENENBAUM, J. M. Extending concurren product and process design toward earlier design stages. In: CHAO, N. H. and LU, S. C. Y. (eds). Concurrent Product and Process Design. Winter Annual Meeting of the ASME, San Francisco, CA p. 65-72, 1989.

DIXON, J. R.; LIBARDI, E. C.; Nielsen, E. $H$. Unresolved research issues in the development of design-with-features systems. In: WOZNY, M. J.; TURNER, J. U. and PREISS, K. (eds.), Geometric Modelling for Product Engineering, Amsterdam, Holland p. 183-196, 1990.

DONG, J.; VIJAVAN, S. Manufacturing feature determination and extraction-Part II Optimal volume segment. Computer Aided Design, 29, p. 427-440, 1997.

DOWLATSHAHI, S. A Comparison of Approaches to Concurrent Engineering, International Jorunal of Advanced Manufac turing Technology, Springer-Verlag, n. 9, p.106-113, 1994.

ELLIS, T.; MOLINA, A.; YOUNG, R. I. M. BELL, R. An information sharing platform for concurrent engineering. In: Integrated Manufacturing System Engineering (Eds. P. Ladet and F. Vernadat), p. 262-277, 1995 (Chapman and Hall, London).

FAUVEL, O. R. Object-oriented design for manufacture. Journal of Intelligent Manufacturing, v. 5, p. 1-11, 1994.

FOWLER, J. STEP for Data Management, Exchange and Sharing. Technology Appraisals, 1995.
GORTI, S. R.; GUPTA, A.; KIM, G. J.; SRIRAM, R. D.; WONG, A. An object-oriented representation for product and design processes. Computer-Aided Design, 1998, v. 30 , n. 7 , p. $489-501$.

GUPTA, S. K.; NAU, D. S. A systematic approach for analysing the manufacturability of machined parts. Computer Aided Design, 27(5), p. 343-342, 1995.

GUPTA, S, K. REGLI, W. C. DAS, D : NAU, D. S. Automated Manufacturability Analysis: A Survey. Research in Engineering Design, 9, p.168-190, 1997.

HSU, W.; LEE, G. C. S.; SU, S. F. Feed back approach to design for assembly by evaluation of assembly plan. Computer Aided Design, 25(7), p. 395-410, 1993.

HUH, Y. J.; KIM, S. G. A knowledge-based CAD system for concurrent product design in injection molding. International Journal of Computer Integrated Manufacturing, 4(4), p. 209-218, 1991.

ISHII, K.; EUBANKS, C. F.; and HOUSER, D. Evaluation methodology for post manufacturing issues in life-cycle design. International Journal of Concurrent Engineering: Research and Applications, 1(1), p. 61-68, 1993.

KRAUSE, F. L.; KIMURA, F.; KJELLBERG, T.; LU, S. C. Y. Product modelling. Annals of the CIRP, 1993, 42(2), p. 695-706.

KRISHNAN, S.; SRIHARI, K. A knowledgebased Object Oriented DFM advisor for surface mount PCB assembly. International Journal Advanced Manufacturing Technology, (ed.) Springer-Verlag London Limited, v. 10, p. 317-329, 1995

LEE, R. J. V.; YOUNG, R. I. M. Information supported design for manufacture of injection-moulded rotational products. International Journal of Production Research, v. 36 , n. 12 , p. $3347-3366,1998$.

LEE, R. J. V. A design for injection moulding strategist in an information modeling environment. Ph.D thesis, Loughborough University, Loughborough, 1996, UK.
LEE, R. S ; CHEN, Y M ; LEE, C. Z Development of a concurrent mould design system: A knowledge-based approach. Computer Integrate Manufacturing Systems, v. 10, n. 4, p. 287-307, 1997.

LENAU, T. The missing element in design for manufacture. Annals of the CIRP, $v$. 45/1, p. 105-108, 1996

LI, R. K.; HWANG, C.L. A framework for automatic DFA system development. Computer In Industry Engineering, 22(4), p. 403-413, 1992.

LU, W. F.; MOLDI, R. Feature-based design in an integrated CAD/CAM system for design for manufacturability of machining prismatic parts. In: Concurrent Product Design and Environmentally Conscious Manufacturing, ASME, 94(5), 1997.

MIYAKAWA, S. Simultaneous engineering and producibility evaluation method. In: Proceedings of the SME internationa conference of application of manufacturing technologies, 1991.

PRATT, S. D.; SIVAKUMAR, M.; MA NOOCHEHRI, S. A knowledge-based engineering system for the design of injection moulded plastic parts. Advances in Design Automation, ASME, 1, p. 287-295, 1993.

PRIEST, J. W.; SANCHEZ, J. M. An empirical methodology for measuring producibility early in product development. International Journal of Computer Integrated Manufacturing, 1991, 4(2), p. 114-120.

ROSENMAN, M. A.; GERO, J. S. Modelling multiple views of design objects in a collaborative design. Computer-Aided Design, 1996, 28, p. 193-205.

SALOMONS, O. W.; HOUTEN, F. J. A. M. V.; KAIS, H. J. J. Review of research in feature-based design. Journal of Manufacturing Systems, 12, p. 113-132, 1993.

SANCHEZ, J. M.; PRIEST, J. W.; SOTO, R. Intelligent reasoning assistant for incorporating manufacturability issues into the design process. Expert Systems with Applications, v. 12, n. 1, p. 81-87, 1997. 
SANCHEZ, J. M.; PRIEST, J. W.; SOTO, R. Intelligent reasoning assistant for incorporating manufacturability issues into the design process. Expert Systems with Applications, v. 12, n. 1, p. 81-87, 1997.

STURGES, R. H.; KILANI, M. I. Towards an integrated design for an assembly evaluation and reasoning system. Computer Aided Design, 24(2), p. 67-79, 1992.

SUBRAMANYAN, S.; LU, S. The Impact of an AI-based design environment for simultaneous engineering on process planning. International Journal of Computer Integrated Manufacturing, 4(2), p. 71-82, 1991.

SUH, N. P. Design axiom and quality control. Robotics and Computer Integrated Manufacturing, 9(4/5), p. 367-376. 1992.

ULLMAN, D. G. The mechanical design process. McGraw-Hill, New York, 1992.
WEINTEN, M.; MANOOCHEHRI, S. Geometric influence of a molded part on the draw direction range and parting line locations. Journal of Mechanical Design, 118, p. 29-39, 1996.

WHITNEY, D. E. Designing the design process. Research in Engineering Design, 2, p. 3-13, 1990

WILLEMS, R.; LECLUSE, D.; KRUTH, J. P. Object oriented information storage for the design of injection moulds. In: Knowledge Intensive $C A D$, v. 1. Proceedings of First IFIP WG 5.2, Finland, p. 188-202, 1995

WOOLDRIDGE, M.; JENNINGS, N. Intelligent agents: theory and practice. Knowledge Engineering Review, 10, p. 115-152, 1995.

WOZNY, M. J.; TURNER, J. U.; GRAVES, R.; DONG, X.; SODHI, R.; DIXON, J.R.; POLI, C.; ROSEN, D.W.; MAHAGAN, P.V.; FATHAILALL, A. A unified representation to support evaluation of designs for ma- nufacturability: Phase III. In: Proceedings of the 1993 National Science Foundation design and manufacturing systems conference, $\mathrm{p}$. 741-753, 1993.

YANNOULAKIS, N. J.; JOSHI, S. B.; WYSK, R.A. Quantitative measures of manufacturability for rotational parts. Transactions of the ASME, Journal of Engineering for Industry, 116(2), p. 189-198, 1994.

YOUNG, R. I. M.; CANCIGLIERI, J., O. COSTA, A.C.; DORADOR, J. M.; ZHAO, J.; CHEUNG, W. M. Information support in an integrated product development system. 3rd International Conference on Integrated Design and Manufacture in Mechanical Engineering (IDMME'2000) Montreal, CD-ROM, paper MA3.1, abst p. $14,2000$.

YOUNG, R. I. M.; CANCIGLIERI, O. J.; COS $\mathrm{TA}, \mathrm{C}$. A. Information interactions in data model driven design for manufacture. In: JACUCCI, G.;OLLING G. J.; PREISS, K. and WOZNY M. (eds), Globalization of Manufacturing in the Digital Communications Er of the 21st Century: Innovation, Agility, and the Virtual Enterprise (Dordrecht: Kluwer), p. 313-324, 1998.

YOUNG, R. I. M. Supporting Multiple Views in Design for Manufacture. IFIP Workshop Series Knowledge Intensive CAD, Second Workshop KIC-2, 1996, September 16-18, Carnegie Mellon University, Pittsburgh, PA, USA.

YOUNG, R. I. M.; CANCIGLIERI, O. J.; COSTA, C. A. Information Interactions in Data Model Driven Design for Manufacture, Globalization of Manufacturing in the Digital Communications Era of the 21st Century: Innovation, Agility, and the Virtual Enterprise, Edited by Jacucci, G. Olling, G. J.; Preiss, K.; Wozny, M. Kluwer Academic Publishers, p. 313-324, ISBN 0 $412835401,1998$.

YOUNG, R. I. M.; CANCIGLIERI, O. J.; COSTA, C. A. Manufacturing information interactions in data model driven design. Proceedings of the Institution of Mechanical Engineers, Part B, Journal of Engineering Manufacture, 213, p. 527532, 1999.

\section{- Sobre o autor}

Osiris Canciglieri Junior, Ph.D.

Pontifícia Universidade Católica do Paraná - Departamento de Engenharia de Produção

Professor Titular no Departamento de Engenharia de Produção

End.: Rua Imaculada Conceição, 1155 - 80215-901

Tel.: (41) 3271-1304

E-mail: osiris.canciglieri@pucpr.br

Young, R. I. M., Ph.D.

Loughborough University - Loughborough, Leicestershire - LE11 3TU - UK

Senior Lecture na Wolfson School of Mechanical and Manufacturing Engineering

E-mail: R.I.Young@lboro.ac.uk. 